\title{
Deeper than shallow: Evidence for structure-based parsing biases in second-language sentence processing
}

\author{
JEFFREY WITZEL and NAOKO WITZEL \\ University of Arizona and University of Texas at Arlington \\ JANET NICOL \\ University of Arizona
}

Received: September 21, 2009 Accepted for publication: December 29, 2010

\section{ADDRESS FOR CORRESPONDENCE}

Jeffrey Witzel, Department of Linguistics \& TESOL, University of Texas at Arlington, Box 19559, 403 Hammond Hall, Arlington, TX 76019. E-mail: jeffrey.witzel@uta.edu

\begin{abstract}
This study examines the reading patterns of native speakers (NSs) and high-level (Chinese) nonnative speakers (NNSs) on three English sentence types involving temporarily ambiguous structural configurations. The reading patterns on each sentence type indicate that both NSs and NNSs were biased toward specific structural interpretations. These results are interpreted as evidence that both first-language and second-language (L2) sentence comprehension is guided (at least in part) by structure-based parsing strategies and, thus as counterevidence to the claim that NNSs are largely limited to rudimentary (or "shallow") syntactic computation during online L2 sentence processing.
\end{abstract}

One of the core questions in second-language (L2) psycholinguistics is how L2 sentence comprehension is accomplished. In order to answer this question, researchers have focused largely on identifying and accounting for the similarities and differences between first-language (L1) and L 2 sentence processing. Although there appears to be considerable overlap in the characteristics of L1 and L2 sentence comprehension, salient L1/L2 processing differences include disparities in global performance (i.e., generally slower and less accurate performance in the L2; among others, see Cook, 1997; Frenck-Mestre, 2002; Hahne \& Friederici, 2001), as well as differential sensitivity to certain morphosyntactic cues (Guillelmon \& Grosjean, 2001; Jiang, 2004, 2007; Liu \& Nicol, 2010; MacWhinney, 2002) and syntactic information (Marinis, Roberts, Felser, \& Clahsen, 2005). These and other differences have been explained in terms of deficient L2 competence, even for highly proficient L2 users (Clahsen \& Felser, 2006a; Jiang, 2004, 2007; but 
see Clahsen \& Felser, 2006b), as well as in terms of differences between the L1 and L2 processing systems. The latter class of accounts appeals to (among other factors) differences in automaticity (Hahne \& Friederici, 2001; Jiang, 2004, 2007; Segalowitz, 2003), differences in the working memory resources available for processing in the L1 versus L2 (Kilborn, 1992), and interference (or transfer) from the L1 (or competition between language systems; Frenck-Mestre \& Pynte, 1997; Juffs, 1998a; Kilborn, 1989; MacWhinney, 2002; but see Barto-Sisamout, Nicol, Witzel, \& Witzel, 2009). Many of these accounts assume that for proficient L2 learners, the representations that the L2 sentence parser computes are essentially the same as those computed for the L1 - the computational mechanism may operate more slowly and less automatically with L2 input, but ultimately, the sentence representations that it creates are similar in terms of hierarchical depth and detail.

However, it is important to consider whether this assumption about the L2 processing system is correct, and more specifically, whether L2 users are able to compute hierarchically deep, detailed syntactic representations during real-time sentence comprehension. One way to approach these questions is to examine the L2 processing of sentences involving structural ambiguities, or sentences that allow (at least temporarily) for more than one structural interpretation. A classic example of this type of structure can be seen in the globally ambiguous sentence, Someone shot the maid of the actress who was on the balcony. In this example, either noun phrase (NP) - the maid or the actress — could be modified by the relative clause (RC) who was on the balcony (or in propositional terms, either of these women could have been on the balcony). In order to arrive at one or the other of these interpretations, the parser must commit to a particular structural analysis of the sentence. Examinations of whether and how these structural commitments are made during online L2 sentence comprehension can therefore provide a window into L2 grammatical processing, just as they have illuminated for decades how sentences are comprehended in an L1.

A number of L1 sentence-processing models have been developed over the years to account for the online structural analysis of these and other sentence types. Most of these models assume that the sentence processor attaches new input into the developing sentence representation more or less immediately (on the assumption that it is burdensome to maintain unstructured elements of a sentence in memory). However, they differ with respect to how these attachment "decisions" are made. Some models posit that these commitments are made in strict accordance with certain phrase-structure-based parsing strategies (or biases) that operate without regard to word meaning, plausibility, or other such information (e.g., so-called syntax-first models; Frazier, 1987a; Frazier \& Rayner, 1982; Mitchell, Cuetos, Corley, \& Brysbaert, 1995). Essentially, these strategies (specific proposals for which will be discussed in some detail below) specify the default structural analyses that the parser is to follow and are motivated primarily by considerations of simplicity, or structure-building economy. Other models suggest that the influence of such structure-based attachment strategies, although important, may be mitigated by considerations of meaning, real-world knowledge, frequency of occurrence, and so forth (e.g., so-called constraint-satisfaction models; Gibson \& Pearlmutter, 1998; MacDonald, Pearlmutter, \& Seidenberg, 
1994; Trueswell \& Tanenhaus, 1994). Yet another type of model holds that a semantic representation of a sentence can be computed (at least initially) without the construction of detailed phrase structure, based on heuristics such as "assume the first noun is the subject of the following verb," coupled with semantic information, lexical information, and real-world knowledge (Bever, 1970; Ferreira, 2003; Ferreira \& Patson, 2007; MacWhinney, 1987; Townsend \& Bever, 2001). ${ }^{1}$

With regard to L2 sentence processing, a recent proposal by Clahsen and Felser (C\&F; 2006a, 2006b, 2006c) holds that the third of these possibilities is the norm. Specifically, their shallow structure hypothesis $(\mathrm{SSH})$ posits that "the syntactic representations adult L2 learners compute for comprehension are shallower and less detailed than those of native speakers," but that "L2 learners are able to draw on their lexical, pragmatic, and world knowledge to build up a semantic or conceptual representation of the sentence" (Clasen \& Felser, 2006b, p. 32). In other words, under this research hypothesis, online L2 sentence comprehension essentially involves establishing the predicate-argument relations conveyed by sentences through the use of "rudimentary" syntactic cues (i.e., through relatively direct form-function mappings), knowledge of lexical properties and meanings, and an understanding of how the world typically works. With respect to the processing of ambiguous sentences, this type of model would be unlikely to posit the use of phrase-structure-based parsing strategies in L2 sentence processing, and this corollary is not only made explicit under current formulations of the SSH but also constitutes one of the primary arguments in support of this theory. Specifically, according to $\mathrm{C} \& \mathrm{~F}$, in order "[for] the parser to be able to make any structurally based attachment decisions, sufficiently detailed, hierarchical representations must be available in the first place" (2006a, p. 113; for a discussion, see also 2006b, pp. 25-27), and, under the SSH, such representations may not be generated during online L2 sentence comprehension.

It is important to note that there are a number of experimental reports demonstrating that nonnative speakers (NNSs) show interpretative biases when processing (temporarily) ambiguous sentences. Under the SSH, however, it is argued that these biases can be accounted for purely in terms of lexicosemantic and pragmatic considerations. For example, several L2 studies have investigated the processing of sentences containing subject/object ambiguities like the following: After Bill drank the water proved to be poisoned (Juffs \& Harrington, 1996; for comparable studies, see Dussias \& Cramer Scaltz, 2008; Felser \& Roberts, 2007; FrenckMestre \& Pynte, 1997; Juffs, 1998b, 2004). In this sentence, both L1 and L2 comprehenders tend to misinterpret the NP the water as the direct object of the optionally transitive verb drank, only to experience processing difficulty, in the form of reading slowdown, when this interpretation is disconfirmed by the main clause verb proved. These findings clearly demonstrate that L 2 comprehenders can be led to a specific interpretation of structurally ambiguous sentences (and "down the garden path," as it were). However, what guides this initial (but ultimately erroneous) interpretation of the postverbal NP as the object of the verb? One possible explanation is that a parsing strategy that favors structural simplicity is at play here. For instance, this apparent bias toward a direct object analysis has been accounted for in terms of a general parsing preference for attachment 
into clauses/phrases that are the current focus of structure-building operations, such as Frazier's late closure (Frazier, 1979; Frazier \& Fodor, 1978) or Kimball's right association (1973). C\&F's claim, however, is that this initial direct object analysis is driven by L2 comprehenders' knowledge of semantic/lexicosemantic information, in this case by the argument structure (or subcategorization properties) of the optionally transitive verb drank. In line with lexically driven accounts for the L1 processing of subject/object ambiguities (MacDonald, Pearlmutter, \& Seidenberg, 1995), C\&F contend that the preference for an object interpretation in these sentences arises because NNSs recognize that the relevant verb (drank) can take an object and that the following NP (the water) can plausibly act as this object. According to $\mathrm{C} \& \mathrm{~F}$ (2006b), the only biases that drive L2 processing decisions are of this type. Specifically, C\&F (2006b) state that "The results from our studies ... indicate that L2 learners differ from . . . native speakers in that they do not rely on structure-based parsing strategies when resolving ambiguities in the L2" (p. 17).

Support for the claim that L2 sentence processing is not guided by purely structural considerations comes from examinations into the L2 processing of sentences involving RC attachment ambiguities. Consider another example of this sentence type: The dean liked the secretary of the professors who was/were reading (Felser, Roberts, Marinis, \& Gross, 2003). As in the example above, in this sentence, the $\mathrm{RC}$ who was/were reading is in a structural position that allows it to modify either the nonlocal NP the secretary (which we term high attachment) or the local NP the professors (which we term low attachment). The RC attachment ambiguity is resolved (or disambiguated) in this case by subject-verb agreement, with was forcing high attachment, and were forcing low attachment. In English, there is a bias, albeit weak and somewhat inconsistent, for low attachment (for indications of this bias, see Carreiras \& Clifton, 1999; Cuetos \& Mitchell, 1988; Frazier \& Clifton, 1996; for indications of no such bias, see Carreiras \& Clifton, 1993; Traxler, Pickering, \& Clifton, 1998), whereas many other languages seem to prefer high attachment (for Spanish, Carreiras \& Clifton, 1999; Cuetos \& Mitchell, 1988; but see Gibson, Pearlmutter, Canseco-Gonzalez, \& Hickok, 1996; for Dutch, Brysbaert \& Mitchell, 1996; for French, Zagar, Pynte, \& Rativeau, 1997).

RC attachment ambiguity sentences are of particular interest because they are arguably capable of teasing out the independent effects of structure-based parsing biases and lexically driven interpretive biases. Although a number of explanations have been advanced in order to account for cross-linguistic differences in RC attachment preferences (see the Discussion Section), one prominent proposal, as well as the proposal of particular interest in the research taken to support the SSH (Felser et al., 2003; Papadopoulou \& Clahsen, 2003), is that they are due to the relative weighting of the structure-based locality principles of recency and predicate proximity (Gibson et al., 1996). Similar to late closure, the principle of recency biases the parser to attach new material to the most recently processed constituent whenever grammatically possible. In sentences involving RC attachment ambiguity, the application of this principle leads to a low attachment bias. Predicate proximity, however, biases the parser to attach modifiers to elements that are structurally closest to the sentential predicate, that is, to arguments of this 
predicate. It is argued that this principle accounts for the high $\mathrm{RC}$ attachment preference attested in certain languages. In addition to these phrase-structure-based parsing strategies, RC attachment also appears to be influenced by the semantic information provided by the preposition that links the component elements in the complex NP. Specifically, when these elements are linked with a preposition like with rather than of (i.e., the secretary with the professors vs. the secretary of the professors), cross-linguistic differences in attachment preferences largely disappear and a consistent low attachment preference is obtained (for off-line studies, see Gilboy, Sopena, Clifton, \& Frazier, 1995; for evidence from online comprehension, see Frenck-Mestre \& Pynte, 2000; Traxler et al., 1998). One explanation for these findings, as well as the account that is explicitly referenced in the studies taken to support the SSH, appeals to construal theory (Frazier \& Clifton, 1996, 1997). This theory holds that prepositions like with establish a distinct thematic processing domain (as opposed to of, which simply assigns/checks case) and that ambiguous RCs, as nonprimary phrases (i.e., elements that do not directly relate to the main predicate and its arguments), are preferentially attached within this local domain.

Consistent with the idea that NNSs are largely limited to shallow syntactic processing, $\mathrm{C} \& \mathrm{~F}$ argue that although $\mathrm{L} 2$ comprehenders are able to use biasing lexical information to guide their online RC attachment preferences, they do not appear to exploit the structure-based parsing biases identified above. For instance, in Felser et al. (2003), proficient Greek-English and German-English learners were tested on sentence types similar to those discussed above: The dean liked the secretary of/with the professors who was/were reading. Both groups of learners showed a clear low RC attachment preference (as evidenced by faster reading times (RTs) for disambiguating verbs that were consistent with this interpretation) when the component elements of the complex NP were linked with the preposition with (the secretary with the professors). However, they showed essentially no attachment preference when these component NPs were linked with the preposition of (the "genitive" construction: the secretary of the professors). These results were interpreted to indicate that, although both learner groups were able to make use of lexical information in their processing of $\mathrm{RC}$ ambiguities, neither group was influenced by predicate proximity, which is the principle that is apparently operative in the processing of these structures in L1 Greek and L1 German, nor were they able to converge on the nativelike processing of these structures according to the recency principle. Comparable results were also obtained in a study examining the L2 processing of Greek sentences involving RC attachment ambiguity by learners from a range of L1 backgrounds (Papadopoulou \& Clahsen, 2003). C\&F (2006b) therefore suggest that when nonstructural cues to interpretation are absent (as in the case of the genitive construction), RC attachments are made "randomly" in L2 sentence processing (p. 18). Based on these findings, C\&F (2006b) further maintain that "There is no independent evidence ... that nonnative comprehenders are guided by phrase structure based parsing principles of the kind that have been attested in L1 processing" (p. 19).

The purpose of the present study is to further explore whether L2 learners show attachment biases in their online processing of syntactically ambiguous sentences. To this end, we examine the eye movements of highly proficient Chinese learners 
of English and a control group of English NSs on three sentence types containing temporarily ambiguous structural configurations: RC attachment ambiguity, adverb attachment ambiguity, and (NP vs. sentence) coordination ambiguity. In each case, it has been claimed that native English speakers are biased in their attachment decisions, in accordance with structure-based parsing principles. Evidence that such biases are attested in L2 sentence processing can be taken to indicate that, during online comprehension, the L2 parser is able to generate hierarchically structured representations with the same depth and detail as those computed by the L1 parser.

\section{SENTENCE TYPES OF INTEREST}

\section{$R C$ attachment (low vs. high)}

As discussed above, the studies conducted by $C \& F$ and colleagues on sentences involving $\mathrm{RC}$ attachment ambiguities suggest that the $\mathrm{L} 2$ processing of this sentence type does not appear to be guided by phrase-structure-based parsing strategies, and in particular, by the principles of recency and predicate proximity. Again, these studies have shown that in the absence of biasing lexical information, highly proficient L2 learners do not show a clear (high or low) RC attachment preference during online sentence comprehension. However, it is important to note that the experimental results for this sentence type are not entirely consistent. Although several studies, including those mentioned above, have failed to find clear attachment preferences in the L2 processing of "nonlexically biased" RC attachment sentences (Dussias, 2003; Felser et al., 2003; Fernández, 2002, 2003; Papadopoulou \& Clahsen, 2003), other studies have found interpretative biases for this sentence type. Specifically, Dussias (2001) found that low-proficient Spanish-English bilinguals prefer high attachment, whereas highly proficient Spanish-English bilinguals prefer low attachment in the processing of L2 English RC attachment sentences. Furthermore, Frenck-Mestre (1999, 2002) showed that low-proficient French-English bilinguals had a low-attachment bias in L2 English RC attachment sentences, and highly proficient English-French bilinguals had a high-attachment bias in L2 French RC attachment sentences. Although Dussias concluded that NNSs are able to apply L2 interpretative biases with increasing proficiency, Frenck-Mestre's work suggests that NNSs are capable of performing like NSs even at earlier stages of L2 development. These inconsistent results are particularly troubling because much of C\&F's argument for "shallow" syntactic computation in L2 sentence processing appears to rest on null findings for this sentence type. Therefore, further examination of sentences involving RC attachment ambiguity is necessary.

The sentences of particular interest in the present study are as follows (with boldface type indicating the point of disambiguation):

(1) a. low attachment

The son of the actress who shot herself on the set was under investigation.

b. high attachment

The son of the actress who shot himself on the set was under investigation. 
In these sentences, the RC who shot herself/himself is in a structural position that allows it to modify either of the component NPs in the complex NP The son of the actress. The appropriate attachment site for the $\mathrm{RC}$ is indicated by antecedent-reflexive gender agreement, where herself signals low attachment to the gender-compatible NP the actress and himself signals high attachment to the gender-compatible NP the son. The elements in the complex NP are linked by of, a preposition that (under construal theory) does not establish a new thematic domain for the local NP (the actress).

The predictions for the processing of these sentences are clear and follow directly from both the empirical work taken to support the SSH (Felser et al., 2003; Papadopoulou \& Clahsen, 2003) as well as the theoretical articles in which this view is explicated (Clahsen \& Felser, 2006a, 2006b). Specifically, according to the SSH, the high-level Chinese learners of English in this study should not preferentially attach the structurally ambiguous RC to either the high NP (the son) or low NP (the actress). That is, again following the analysis put forward under the SSH for these sentences (see above), in the absence of biasing lexical information, the L2 processing of these sentences should not be guided by structure-based locality principles (i.e., by either recency or predicate proximity). Such findings would be consistent with the central SSH tenet that NNSs do not compute structural representations of sufficient depth and detail in order for structure-based parsing strategies to be operative during online L2 sentence comprehension. Alternatively, and following the same logic that has been used to argue that native speaker comprehension is guided by parsing strategies, any indication of an attachment preference in accordance with these structure-based parsing principles would suggest that L2 sentence processing involves the computation of rich syntactic structure.

It is important to note several features of the materials and methodology used in the present study that allow for an adequate test of these predictions. As pointed out above, antecedent-reflexive gender agreement was used to disambiguate; that is, to force a particular attachment. This was done for several reasons. In other experiments conducted in our lab (Liu \& Nicol, 2010), Chinese learners of English, who are the L2 learners of interest in the present study, have shown sensitivity to reflexive-antecedent gender agreement during online L2 sentence comprehension. Specifically, in a self-paced reading task, these NNSs had reliably longer RTs immediately after reflexives that mismatched their antecedents in terms of gender. That same study showed a reduced effect with number (dis)agreement (e.g., The girls . . . herself). Note also that gender agreement was used in the materials tested by Papadopoulou and Clahsen (2003), one of the studies that has been taken as support for the SSH. Their investigation of RC attachment biases in L2 Greek used noun-adjective/participle gender agreement as disambiguating information. English antecedent-reflexive gender agreement is analogous to this agreement type; both types of gender agreement are obligatory and presumably draw on comparable information sources. Another feature of our materials is that the complex NP (preceding the RC) appears in subject position, whereas in previous L2 studies examining RC attachment biases (or lack thereof), the complex NP was the object of the main verb (Dussias, 2001; Felser et al., 2003; Fernández, 2002, 2003; Frenck-Mestre, 1999, 2002; Papadopoulou \& Clahsen, 2003). We specifically 
chose subject modification in order to minimize potentially confounding sources of contextual information available to the reader upon encountering the $\mathrm{RC}$. That is, it is conceivable that readers would develop some expectations about the noun to be modified based in part on context, and that these expectations could interact with default RC attachment biases.

In order to increase the likelihood of detecting an attachment bias, the present study also used an eye-tracking methodology (described in detail below). It is important to point out that all of the studies that have failed to find online attachment preferences for L2 comprehenders have used a self-paced, word by word or phrase by phrase, moving-window reading methodology (Dussias, 2003; Felser et al., 2003; Fernández, 2002, 2003; Papadopoulou \& Clahsen, 2003), whereas two of (the admittedly few) studies that have shown these attachment biases have used eye tracking (Frenck-Mestre, 1999, 2002). Even in L1 studies investigating RC attachment preferences, RT differences between high versus low RC attachment sentences are often subtle (and as mentioned above, sometimes nonexistent) and appear to be revealed more consistently in eye tracking than in self-paced reading (for discussion, see Carreiras \& Clifton, 1999). In order to test whether L2 comprehenders show a bias for high or low RC attachment, it is necessary to use a method that is at least capable of revealing differences in the processing of these sentence types.

\section{Adverb attachment (low vs. high)}

The second sentence type of interest also contains a syntactic constituent that could be attached either locally or nonlocally. In this case, the relevant constituent is an adverb phrase (AdvP) in a position that permits attachment either to a local verb phrase (VP) or to a nonlocal VP. For example, consider the (globally) ambiguous sentence Jack met the friend he phoned last week. This sentence is ambiguous as to whether Jack met this friend last week or phoned this friend last week. That is, the AdvP last week can attach to the higher VP met the friend or to the lower VP phoned. In the temporarily ambiguous sentences tested in the present study, the attachment position for this phrase is determined by the respective tenses of the high and low VP, as in the following examples:

(2) a. low attachment

Jack will meet the friend he phoned yesterday, but he doesn't want to.

b. high attachment

Jack will meet the friend he phoned tomorrow, but he doesn't want to.

In (2a) the AdvP yesterday is consistent only with the tense of the lower VP phoned, whereas in (2b) the AdvP tomorrow is consistent only with the tense of the higher VP will meet the friend.

Previous eye-tracking research on these sentence types has indicated that English NSs are biased toward low attachment for this AdvP, even in the presence of contextual information that strongly supports high attachment (Altmann, van Nice, Garnham, \& Henstra, 1998). These results are in line with what appears to be a fairly consistent preference across languages to attach VP modifiers locally. 
That is, with reference again to Gibson's locality principles, although languages differ in terms of the relative weighting of predicate proximity and recency for the attachment of NP modifiers (such as RCs, see above), recency is the only principle relevant to the processing of VP modifiers (for discussion, see Gibson et al., 1996, p. 41). A relevant question then is whether NNSs would indicate a low attachment bias for VP modifiers in accordance with this principle. Again, the SSH holds that L2 processing is not guided by structure-based parsing biases of this type, and therefore, this theory again predicts that NNSs should show no attachment preference in sentences involving AdvPs in structurally ambiguous positions. If, however, the relevant structure-based locality principle of recency is operative during online L2 sentence processing, NNSs should show a low attachment bias on this sentence type. To the extent that indications of such parsing strategies can be taken as a diagnostic of deep syntactic processing, such results would provide support for the assertion that online L2 comprehension is characterized by the computation of detailed structural representations and of abstract relationships between those representations.

\section{$N P$ versus sentence coordination}

The last sentence type of interest involves coordination ambiguity. Consider the sentence fragment The nurse examined the mother and the child. . . . At this point in the sentence, the child can be interpreted either as the second member of a conjoined direct object NP (The nurse examined the mother and the child at the hospital) or as the subject of a conjoined clause (The nurse examined the mother and the child played quietly in the corner). The present experiment tested the following sentences related to this coordination ambiguity:

(3) a. unambiguous (comma):

The nurse examined the mother, and the child played quietly in the corner.

b. temporarily ambiguous:

The nurse examined the mother and the child played quietly in the corner.

In the unambiguous sentence (3a), the structural position of the NP (the child) immediately following the conjunction and is clearly indicated by the presence of a comma. This punctuation separates the two clauses of the sentence and thus establishes this NP as the subject of the second clause well before information provided by the second VP (played quietly in the corner) becomes available. In the temporarily ambiguous sentence ( $3 \mathrm{~b})$, however, this disambiguating punctuation is not provided. Therefore, in this sentence type, the structural position/grammatical function of the NP immediately following the conjunction and (the child) is not clear until it needs to be linked with the second VP (played quietly in the corner).

Of particular interest is whether NNSs would show processing difficulty on the temporarily ambiguous version of these sentences when the coordinated direct object interpretation is disconfirmed by the verb in second clause (played). Such results would match well with both self-paced reading and eye-tracking studies showing that readers prefer the conjoined NP interpretation over the coordinate clause interpretation in both English (Frazier \& Clifton, 1997) and Dutch (Frazier, 
1987b; Hoeks, Hendriks, Vonk, Brown, \& Hagoort, 2006). These findings are consistent with the principle of minimal attachment, which directs the parser to posit the fewest syntactic nodes necessary in the attachment of a new constituent. In coordination ambiguity sentences such as those above, this principle leads the parser to continue with a single-clause analysis of the sentence (and thus to interpret the structurally ambiguous NP as part of the direct object of this sentence) until it is forced to reject and revise this analysis (for more on this interpretation, Frazier, 1987b; Frazier \& Clifton, 1997; Hoeks et al., 2006). Note the similarity between this construction and sentences involving subject/object ambiguities: After Bill drank the water proved to be poisoned. As discussed above, although the preferred attachment in subject/object ambiguity sentences may be characterized in purely syntactic terms, an alternative "shallow structure" characterization has to do with the fact that the verb drank can take a direct object, and the NP the water satisfies this requirement. In these coordination constructions, however, the first postverbal NP has already satisfied the verb's requirement for a direct object. Hence, the same alternative characterization does not apply.

It is important to note that, at several points in the discussion of the SSH (see Clahsen \& Felser, 2006a, pp. 117 and 120), C\&F mention minimal attachment as one of the principles that, although operative in L1 sentence processing, does not guide online L2 sentence comprehension. Specifically, they argue that "the L2 parser will be unable to successfully apply even universal processing mechanisms (such as minimal attachment) if the L2 grammar fails to provide sufficient grammatical information" (Clahsen \& Felser, 2006a, p. 120). The present study sought to test this claim directly by examining the L2 processing of sentences that have been taken to indicate the minimal attachment principle at work. Again, the clear prediction of the SSH is that the L2 processing of these sentences is not guided by the structure-based parsing principle of minimal attachment, and thus, that NNSs should indicate no preference for a coordinate NP interpretation of the temporarily ambiguous constituent. Alternatively, reading patterns consistent with a default NP coordination interpretation would suggest that NNSs are able to deploy this parsing strategy and, by extension, that they are able to compute structural representations of sufficient depth and detail for this strategy to work.

\section{EXPERIMENT}

\section{Method}

Participants. All participants were affiliated with the University of Arizona. For the NS group, 30 undergraduate students ( 9 men, 21 women; mean age $=19.70$ ) participated in partial fulfillment of course requirements. For the NNS group, 30 highly proficient Chinese learners of English (5 men, 25 women; mean age = 28.70), who were students or staff members at the university, participated in exchange for a small monetary award. The student participants in this NNS group were international students (from China and Taiwan) in degree-granting undergraduate and graduate programs, with Test of English as a Foreign Language scores of at least 500 (Paper-Based Test), 61 (Internet-Based Test), or 173 (Computer-Based Test). The staff members in this group (also from China and 
Taiwan) were researchers and faculty members, each of whom had received a graduate degree from a university in the United States. All of these NNS participants were late learners of English, who began studying the language in middle school (between the ages of 10 to 12) and whose questionnaire responses indicated that they had achieved L2 "fluency" on average at the age of 20. All participants had normal or corrected to normal vision.

Materials and design. Twenty-four items were created for each of the three sentence types: RC attachment, adverb attachment, and NP versus sentence coordination (provided in Appendices A, B, and C, respectively). Each item appeared in two conditions, which were counterbalanced over two lists. In the RC attachment sentences, the gender of the (disambiguating) reflexive was balanced such that himself and herself were equally associated with each attachment type. Likewise, in the adverb attachment sentences, adverb phrases indicating past and future (yesterday/tomorrow, last week/next week, and last month/next month) were equally associated with each attachment type. In addition to the experimental items, 24 fillers were created. These filler items included sentences with RCs and time adverbials in structurally unambiguous positions, as well as various types of coordination, and were included to distract participants from the purpose(s) of the experiment. In sum, there were 96 sentences in the experiment. Half of these sentences were followed by YES/NO comprehension questions. Items were presented to participants in 24 blocks, each consisting of 4 sentences (see the Procedure Section below). Experimental and filler items were presented essentially at random throughout the experiment, with the only restriction being that no more than two experimental items occurred in succession in any block.

Procedure. Sentences were presented as single lines of text (with standard capitalization and punctuation) on a 21-in. CRT monitor. Participants were instructed to read each sentence silently at their natural reading speed, making sure to comprehend well enough to accurately answer occasional YES/NO questions. Eye movements were recorded from the right eye using a Dr. Bouis Monocular Oculometer at a sampling rate of $200 \mathrm{~Hz}$. The distance from the participant's eye to the monitor was approximately $60 \mathrm{~cm}$, which allowed for single-character resolution. A bite plate and headrest were used to minimize head movements. The eye tracker was calibrated at the beginning of the experiment and then recalibrated after every four trials. Each trial began with a fixation mark (an asterisk) near the left edge of the computer screen. A sentence would then display, with its first character one space to the left of the fixation point. Participants pushed a button under their right hand as soon as they had finished reading each sentence, at which point the sentence disappeared from the screen. If the sentence was not followed by a YES/NO comprehension question, a string of dashes appeared on the screen, signaling the participant to proceed to the next trial when ready by again pressing the right button. If the item was followed by a comprehension check, participants answered YES with the right button or NO with a button under the left hand. The participants then received feedback, and the next trial began automatically. At the beginning of the task, participants were given eight practice trials. 
Table 1. Mean (standard deviations) total sentence RTs for native speakers on all three sentence types and corresponding analysis of variance results

\begin{tabular}{lllcc}
\hline \hline & & Total Sentence RT & $F 1$ & $F 2$ \\
\hline Relative clause & Low attachment & $3727(947)$ & 2.78 & 3.37 \\
$\quad$ attachment & High attachment & $3887(983)$ & & \\
Adverb attachment & Low attachment & $3231(614)$ & $36.05^{* * *}$ & $48.82^{* * * *}$ \\
\multirow{2}{*}{$\begin{array}{l}\text { Noun phrase vs. } \\
\text { sentence coordination }\end{array}$} & High attachment & $3697(774)$ & & \\
\hline \hline
\end{tabular}

Note: RTs, reading times.

$* * p<.01 . * * * p<.001$.

Data analysis. No participant had a comprehension question error rate of greater than $20 \%$. The mean accuracy rate for NSs was $91 \%$, whereas for NNSs it was $90 \%$ $(F<1)$. Trials with major tracker losses were excluded from the analysis. These trials accounted for $4.34 \%$ of the experimental items (2.87\% of the experimental trials for the NS group; $5.81 \%$ for the NNS group). ${ }^{2}$ Five eye-tracking measures are reported below: first-pass RT, go-past RT, total RT, first-pass regression proportion and total sentence $R T$. First-pass RT is the sum of the fixation durations in a region after entering that region until leaving it in any direction. Go-past RT (also known as regression-path $R T$ ) is the sum of all of the fixation durations after entering a region until leaving that region to the right. This measure includes regressive fixations to previous regions. Total RT is the sum of all fixation durations in a region. First-pass regression proportion refers to the proportion of trials on which the reader had a regressive eye movement from a given region to a previous region during the initial pass through the sentence. Total sentence RT refers to the sum of all of the fixation durations for the sentence. This measure provides a global indication of the processing characteristics associated with the sentence types of interest. Each of the RT measures included all of the relevant fixations, that is, fixation durations below a certain minimum cutoff value were not eliminated from these measures. For each measure in the sentences of interest, two analyses of variance (ANOVAs) were conducted, one with subjects $(F 1)$ and the other with items $(F 2)$ as a random variable. List/item group was also included as a nonrepeated factor in these analyses in order to remove the variability associated with the counterbalancing procedures.

\section{Results}

$R C$ attachment. For RC attachment sentences, attachment site (low, high) was a repeated measure. Total sentence RTs for this sentence type are presented in Table 1 for NSs, and in Table 2 for NNSs. The mean first-pass RTs, go-past RTs, total RTs, and first-pass regression proportions for these sentences are presented (by condition and region) in Table 3 for NSs, and in Table 4 for NNSs. The 
Table 2. Mean (standard deviations) total sentence RTs for nonnative speakers on all three sentence types and corresponding analysis of variance results

\begin{tabular}{llccc}
\hline \hline & & Total Sentence RT & $F 1$ & $F 2$ \\
\hline Relative clause & Low attachment & $4918(961)$ & $5.45^{*}$ & $4.45^{*}$ \\
$\quad$ attachment & High attachment & $4704(763)$ & & \\
Adverb attachment & Low attachment & $4224(780)$ & $35.31^{* * *}$ & $28.60^{* * *}$ \\
Noun phrase vs. & High attachment & $4610(794)$ & & \\
$\quad$ Sentence coordination & Anambiguous & $4413(811)$ & $7.66^{* *}$ & $19.85^{* * *}$ \\
& Ambiguous & $4696(905)$ & & \\
\hline \hline
\end{tabular}

Note: RTs, reading times.

$* p<.05 . * * p<.01 . * * * p<.001$.

Table 3. Native speaker means (standard deviations) for relative clause sentences

\begin{tabular}{|c|c|c|c|c|c|}
\hline & \multicolumn{5}{|c|}{ Region } \\
\hline & 1 & 2 & 3 & 4 & 5 \\
\hline & \multicolumn{5}{|c|}{ Low Attachment } \\
\hline & The son & $\begin{array}{l}\text { of the } \\
\text { actress }\end{array}$ & $\begin{array}{l}\text { who shot } \\
\text { herself }\end{array}$ & on the set & $\begin{array}{l}\text { was under. } \\
\text { investigation. }\end{array}$ \\
\hline & \multicolumn{5}{|c|}{ High Attachment } \\
\hline & The son & $\begin{array}{l}\text { of the } \\
\text { actress }\end{array}$ & $\begin{array}{l}\text { who shot } \\
\text { himself }\end{array}$ & on the set & $\begin{array}{l}\text { was under. } \\
\text { investigation. }\end{array}$ \\
\hline \multicolumn{6}{|c|}{ First-pass reading times } \\
\hline Low attachment & $318(75)$ & $423(102)$ & 724 (157) & $460(118)$ & 655 (192) \\
\hline High attachment & $316(79)$ & 439 (101) & 744 (137) & 489 (120) & $633(178)$ \\
\hline \multicolumn{6}{|l|}{ Go-past reading times } \\
\hline Low attachment & & 449 (116) & $860(184)$ & $581(172)$ & $584(164)$ \\
\hline High attachment & & $488(140)$ & $885(220)$ & $634(173)$ & $586(137)$ \\
\hline \multicolumn{6}{|l|}{ Total time in region } \\
\hline Low attachment & 449 (134) & $695(231)$ & $1094(311)$ & $688(252)$ & $802(225)$ \\
\hline High attachment & $469(158)$ & $753(246)$ & $1175(405)$ & 709 (169) & $781(198)$ \\
\hline \multicolumn{6}{|c|}{ First-pass regression proportion } \\
\hline Low attachment & & $.04(.07)$ & $.13(.12)$ & $.14(.12)$ & \\
\hline High attachment & & $.07(.10)$ & $.13(.12)$ & $.16(.14)$ & \\
\hline
\end{tabular}

results of the ANOVAs for each of these measures in each region are presented in Table 5 for NSs, and in Table 6 for NNSs.

For the English NSs, there was a statistically unreliable trend suggesting longer total sentence RTs under high attachment sentences, $F 1(1,28)=2.78, p=.10$, $F 2(1,22)=3.37, p=.08$. In the per-region measures, the earliest statistically 
Table 4. Nonnative speaker means (standard deviations) for relative clause sentences

\begin{tabular}{|c|c|c|c|c|c|}
\hline & \multicolumn{5}{|c|}{ Region } \\
\hline & 1 & 2 & 3 & 4 & 5 \\
\hline & \multicolumn{5}{|c|}{ Low Attachment } \\
\hline & The son & $\begin{array}{l}\text { of the } \\
\text { actress }\end{array}$ & $\begin{array}{l}\text { who shot } \\
\text { herself }\end{array}$ & on the set & $\begin{array}{l}\text { was under. } \\
\text { investigation. }\end{array}$ \\
\hline & \multicolumn{5}{|c|}{ High Attachment } \\
\hline & The son & $\begin{array}{l}\text { of the } \\
\text { actress }\end{array}$ & $\begin{array}{l}\text { who shot } \\
\text { himself }\end{array}$ & on the set & $\begin{array}{l}\text { was under. } \\
\text { investigation. }\end{array}$ \\
\hline \multicolumn{6}{|c|}{ First-pass reading times } \\
\hline Low attachment & $314(88)$ & $512(144)$ & $1127(261)$ & $646(132)$ & $816(195)$ \\
\hline High attachment & $304(69)$ & $516(181)$ & 1059 (264) & $628(136)$ & $864(240)$ \\
\hline \multicolumn{6}{|c|}{ Go-past reading times } \\
\hline Low attachment & & $548(161)$ & $1390(413)$ & $821(214)$ & $815(200)$ \\
\hline High attachment & & $542(196)$ & $1317(382)$ & 790 (157) & $835(181)$ \\
\hline \multicolumn{6}{|l|}{ Total time in region } \\
\hline Low attachment & $486(174)$ & $869(264)$ & $1610(380)$ & $930(244)$ & $1022(247)$ \\
\hline High attachment & $437(135)$ & $838(229)$ & 1499 (338) & $874(163)$ & $1056(267)$ \\
\hline \multicolumn{6}{|c|}{ First-pass regression proportion } \\
\hline Low attachment & & $.05(.07)$ & $.17(.15)$ & $.15(.13)$ & \\
\hline High attachment & & $.03(.06)$ & $.17(.14)$ & $.16(.16)$ & \\
\hline
\end{tabular}

reliable difference was revealed for go-past RT in Region $2, F 1(1,28)=6.32$, $p<.05, F 2(1,22)=5.95, p<.05$, with high attachment sentences again read more slowly. However, because this region (immediately) precedes the critical region, this result does not lend itself to clear interpretation (see the Discussion Section). In the critical region, Region 3, total RT was significantly longer for high attachment sentences than for low attachment sentences, $F 1(1,28)=4.39, p<$ $.05, F 2(1,22)=5.62, p<.05$, indicating a low $\mathrm{RC}$ attachment bias.

The pattern of results for the Chinese learners indicated an attachment bias in the opposite direction. For this NNS group, total sentence RT was significantly longer for low attachment sentences, $F 1(1,28)=5.45, p<.05, F 2(1,22)=4.45$, $p<.05$. Furthermore, at the critical region, Region 3, total RT was longer for low attachment sentences than for high attachment sentences, $F 1(1,28)=5.46, p<$ $.05, F 2(1,22)=6.00, p<.05$. Low attachment sentences also had longer total RTs in Region $1, F 1(1,28)=7.64, p<.05, F 2(1,22)=4.30, p<.05$, suggesting that these NNSs spent more time checking the head of the complex subject NP when it was incompatible with high RC attachment. This pattern of results thus indicates a high RC attachment bias for these Chinese learners of English.

In sum, both the NSs and NNSs showed a bias for a particular attachment site when processing sentences containing RCs in structurally ambiguous positions. 
Table 5. Analysis of variance results for relative clause sentences in native speakers

\begin{tabular}{lcc}
\hline \hline & \multicolumn{2}{c}{ Attachment Preference } \\
\cline { 2 - 3 } & $F 1(1,28)$ & $F 2(1,22)$ \\
& & \\
\hline Region 1 & $<1$ & $<1$ \\
First-pass reading times & & \\
Go-past reading times & 1.07 & 1.34 \\
Total time in region & & \\
Regression proportion & & \\
Region 2 & & 1.63 \\
First-pass reading times & 1.34 & $5.95^{*}$ \\
Go-past reading times & $6.32^{*}$ & 3.34 \\
Total time in region & 3.88 & 2.72 \\
Regression proportion & 1.92 & $<1$ \\
Region 3 & & 1.14 \\
First-pass reading times & $<1$ & $5.62^{*}$ \\
Go-past reading times & 1.22 & $<1$ \\
Total time in region & $4.39 *$ & \\
Regression proportion & $<1$ & 3.45 \\
Region 4 & & 2.22 \\
First-pass reading times & $4.20^{*}$ & $<1$ \\
Go-past reading times & 2.40 & $<1$ \\
Total time in region & $<1$ & 1.25 \\
Regression proportion & $<1$ & $<1$ \\
Region 5 & & \\
First-pass reading times & $<1$ & $<1$ \\
Go-past reading times & $<1$ & \\
Total time in region & & \\
Regression proportion & & \\
\hline \hline
\end{tabular}

${ }^{a}$ First-pass regression proportion.

$* p<.05$.

However, this bias was in the opposite direction for the two participant groups: NSs showed a low attachment bias, while NNSs showed a high attachment bias.

Adverb attachment. In the statistical analyses for adverb attachment sentences, attachment site (low, high) was again a repeated measure. Total sentence RTs for this sentence type are presented in Table 1 for NSs, and in Table 2 for NNSs. The mean first-pass RTs, go-past RTs, total RTs, and first-pass regression proportions for these sentences are presented (by condition and region) in Table 7 for NSs, and in Table 8 for NNSs. The results of the ANOVAs for each of these measures in each region are presented in Table 9 for NSs, and in Table 10 for NNSs.

For the NS group, total sentence RT was longer for high attachment sentences than for low attachment sentences, $F 1(1,28)=36.05, p<.001, F 2(1,22)=$ 48.82, $p<.001$. Furthermore, in the critical region of the time adverbial, 
Table 6. Analysis of variance results for relative clause sentences in nonnative speakers

\begin{tabular}{lcc}
\hline \hline & \multicolumn{2}{c}{ Attachment Preference } \\
\cline { 2 - 3 } & $F 1(1,28)$ & $F 2(1,22)$ \\
\hline Region 1 & & \\
$\quad$ First-pass reading times & $<1$ & $<1$ \\
Go-past reading times & & \\
Total time in region & $7.64^{*}$ & $4.30^{*}$ \\
Regression proportion & & \\
Region 2 & & \\
First-pass reading times & $<1$ & $<1$ \\
Go-past reading times & $<1$ & $<1$ \\
Total time in region & $<1$ & 1.23 \\
Regression proportion & $<1$ & \\
Region 3 & & 2.91 \\
First-pass reading times & $5.02^{*}$ & 1.65 \\
Go-past reading times & 2.74 & $6.00^{*}$ \\
Total time in region & $5.46^{*}$ & $<1$ \\
Regression proportion & $<1$ & $<1$ \\
Region 4 & & $<1$ \\
First-pass reading times & $<1$ & 1.40 \\
Go-past reading times & $<1$ & $<1$ \\
Total time in region & 1.87 & 4.05 \\
Regression proportion & $<1$ & 1.18 \\
Region 5 & & \\
First-pass reading times & 2.88 & $<1$ \\
Go-past reading times & 1.53 & \\
Total time in region & & \\
Regression proportion & & \\
\hline \hline
\end{tabular}

${ }^{a}$ First-pass regression proportion. $* p<.05$.

Region 4, there were longer first-pass, go-past, and total RTs, and a greater proportion of first-pass regressions for high attachment sentences: first-pass RT, $F 1$ $(1,28)=10.71, p<.01, F 2(1,22)=13.37, p<.01$; go-past RT, $F 1(1,28)=$ $26.99, p<.001, F 2(1,22)=27.22, p<.001$; total RT, $F 1(1,28)=37.10, p<$ $.001, F 2(1,22)=40.37, p<.001$; first-pass regression proportion, $F 1(1,28)=$ $16.82, p<.001, F 2(1,22)=17.31, p<.001$. The same pattern of results was also found in the immediately following region, Region 5: first-pass RT, $F 1$ (1, $28)=4.39, p<.05, F 2(1,22)=19.60, p<.001$; go-past RT, $F 1(1,28)=32.47$, $p<.001, F 2(1,22)=53.12, p<.001$; total RT, $F 1(1,28)=23.49, p<.001$, $F 2(1,22)=34.20, p<.001$; first-pass regression proportion, $F 1(1,28)=42.53$, $p<.001, F 2(1,22)=25.82, p<.001$. High attachment sentences also incurred longer total RTs in Regions 2 and 3: Region 2, $F 1(1,28)=8.29, p<.01, F 2(1$, $22)=8.68, p<.01$; Region $3, F 1(1,28)=18.74, p<.001, F 2(1,22)=37.56$, 
Table 7. Native speakers means (standard deviations) for adverb attachment sentences

\begin{tabular}{|c|c|c|c|c|c|c|}
\hline & \multicolumn{6}{|c|}{ Region } \\
\hline & 1 & 2 & 3 & 4 & 5 & 6 \\
\hline & \multicolumn{6}{|c|}{ Low Attachment } \\
\hline & Jack will meet & the friend & he phoned & yesterday, & but he doesn't & want to. \\
\hline & \multicolumn{6}{|c|}{ High Attachment } \\
\hline & Jack will meet & the friend & he phoned & tomorrow, & but he doesn't & want to. \\
\hline \multicolumn{7}{|c|}{ First-pass reading times } \\
\hline Low attachment & $527(122)$ & $336(82)$ & $484(122)$ & $304(53)$ & $522(123)$ & $485(134)$ \\
\hline High attachment & $532(117)$ & 357 (107) & $510(121)$ & $344(82)$ & $580(176)$ & $440(127)$ \\
\hline \multicolumn{7}{|l|}{ Go-past reading times } \\
\hline Low attachment & & $382(110)$ & 557 (148) & $350(85)$ & 557 (139) & $474(124)$ \\
\hline High attachment & & $396(123)$ & $589(144)$ & $524(196)$ & $759(254)$ & $435(132)$ \\
\hline \multicolumn{7}{|l|}{ Total time in region } \\
\hline Low attachment & $625(145)$ & 439 (127) & $608(165)$ & $354(87)$ & $656(139)$ & $549(151)$ \\
\hline High attachment & $639(148)$ & $492(130)$ & 769 (238) & 488 (158) & $801(210)$ & $510(142)$ \\
\hline \multicolumn{7}{|c|}{ First-pass regression proportion } \\
\hline Low attachment & & $.10(.10)$ & $.10(.09)$ & $.10(.12)$ & $.04(.05)$ & \\
\hline High attachment & & $.07(.07)$ & $.10(.09)$ & $.24(.17)$ & $.15(.11)$ & \\
\hline
\end{tabular}


Table 8. Nonnative speaker means (standard deviations) for adverb attachment sentences

\begin{tabular}{|c|c|c|c|c|c|c|}
\hline & \multicolumn{6}{|c|}{ Region } \\
\hline & 1 & 2 & 3 & 4 & 5 & 6 \\
\hline & \multicolumn{6}{|c|}{ Low Attachment } \\
\hline & Jack will meet & the friend & he phoned & yesterday, & but he doesn't & want to. \\
\hline & \multicolumn{6}{|c|}{ High Attachment } \\
\hline & Jack will meet & the friend & he phoned & tomorrow, & but he doesn't & want to. \\
\hline \multicolumn{7}{|c|}{ First-pass reading times } \\
\hline Low attachment & $548(149)$ & $436(169)$ & $648(182)$ & $426(102)$ & $650(155)$ & $629(199)$ \\
\hline High attachment & $574(129)$ & 430 (139) & 585 (173) & $455(95)$ & $684(144)$ & $625(180)$ \\
\hline \multicolumn{7}{|l|}{ Go-past reading times } \\
\hline Low attachment & & $557(216)$ & $761(217)$ & $559(158)$ & $771(213)$ & $610(181)$ \\
\hline High attachment & & $510(174)$ & $783(216)$ & $622(176)$ & $967(282)$ & $613(161)$ \\
\hline \multicolumn{7}{|l|}{ Total time in region } \\
\hline Low attachment & $694(207)$ & $622(210)$ & $833(203)$ & $555(150)$ & $822(151)$ & $698(211)$ \\
\hline High attachment & $726(195)$ & $644(215)$ & 894 (206) & $645(182)$ & 988 (209) & $713(194)$ \\
\hline \multicolumn{7}{|c|}{ First-pass regression proportion } \\
\hline Low attachment & & $.17(.13)$ & $.11(.12)$ & $.20(.14)$ & $.12(.12)$ & \\
\hline High attachment & & $.10(.11)$ & $.20(.15)$ & $.23(.15)$ & $.20(.16)$ & \\
\hline
\end{tabular}


Table 9. Analysis of variance results for adverb attachment sentences in native speakers

\begin{tabular}{|c|c|c|}
\hline & \multicolumn{2}{|c|}{ Attachment Preference } \\
\hline & $F 1(1,28)$ & $F 2(1,22)$ \\
\hline \multicolumn{3}{|l|}{ Region 1} \\
\hline $\begin{array}{l}\text { First-pass reading times } \\
\text { Go-past reading times }\end{array}$ & $<1$ & $<1$ \\
\hline $\begin{array}{l}\text { Total time in region } \\
\text { Regression proportion }^{a}\end{array}$ & $<1$ & $<1$ \\
\hline \multicolumn{3}{|l|}{ Region 2} \\
\hline First-pass reading times & 2.87 & 1.94 \\
\hline Go-past reading times & $<1$ & $<1$ \\
\hline Total time in region & $8.29 * *$ & $8.68 * *$ \\
\hline Regression proportion & 2.22 & 1.54 \\
\hline \multicolumn{3}{|l|}{ Region 3} \\
\hline First-pass reading times & 2.76 & 1.40 \\
\hline Go-past reading times & 2.60 & 1.73 \\
\hline Total time in region & $18.74 * * *$ & $37.56^{* * *}$ \\
\hline Regression proportion & $<1$ & $<1$ \\
\hline \multicolumn{3}{|l|}{ Region 4} \\
\hline First-pass reading times & $10.71 * *$ & $13.37 * *$ \\
\hline Go-past reading times & $26.99 * * *$ & $27.22 * * *$ \\
\hline Total time in region & $37.10 * * *$ & $40.37 * * *$ \\
\hline Regression proportion & $16.82 * * *$ & $17.31 * * *$ \\
\hline \multicolumn{3}{|l|}{ Region 5} \\
\hline First-pass reading times & $4.39 *$ & $19.60 * * *$ \\
\hline Go-past reading times & $32.47 * * *$ & $53.12 * * *$ \\
\hline Total time in region & $23.49 * * *$ & $34.20 * * *$ \\
\hline Regression proportion & $42.53 * * *$ & $25.82 * * *$ \\
\hline \multicolumn{3}{|l|}{ Region 6} \\
\hline First-pass reading times & $4.46^{*}$ & $6.58 *$ \\
\hline Go-past reading times & $4.26 *$ & $7.14 *$ \\
\hline Total time in region & 2.72 & $4.92 *$ \\
\hline Regression proportion & & \\
\hline
\end{tabular}

${ }^{a}$ First-pass regression proportion.

$* p<.05 . * * p<.01 . * * * p<.001$.

$p<.001$, indicating longer times spent checking these sections after regressive eye movements. In this case, these longer total RTs likely reflect "tense checking" when the time adverbial mismatched with the tense of the local (low) VP. In the final region of the sentences, Region 6, there were significant differences between the sentence types in terms of first-pass RT and go-past RT: first-pass RT, $F 1$ $(1,28)=4.46, p<.05, F 2(1,22)=6.58, p<.05$; go-past RT, $F 1(1,28)=$ $4.26, p<.05, F 2(1,22)=7.14, p<.05$. However, these differences were in the opposite direction of those found in the other regions of these sentence types, that 
Table 10. Analysis of variance results for adverb attachment sentences in nonnative speakers

\begin{tabular}{|c|c|c|}
\hline & \multicolumn{2}{|c|}{ Attachment Preference } \\
\hline & $F 1(1,28)$ & $F 2(1,22)$ \\
\hline \multicolumn{3}{|l|}{ Region 1} \\
\hline First-pass reading times & 1.19 & $<1$ \\
\hline Go-past reading times & & \\
\hline $\begin{array}{l}\text { Total time in region } \\
\text { Regression proportion }\end{array}$ & 1.04 & $<1$ \\
\hline \multicolumn{3}{|l|}{ Region 2} \\
\hline First-pass reading times & $<1$ & $<1$ \\
\hline Go-past reading times & 2.48 & $5.15^{*}$ \\
\hline Total time in region & $<1$ & $<1$ \\
\hline Regression proportion & $6.51 *$ & $23.73 * * *$ \\
\hline \multicolumn{3}{|l|}{ Region 3} \\
\hline First-pass reading times & $4.93 *$ & $6.12 *$ \\
\hline Go-past reading times & $<1$ & $<1$ \\
\hline Total time in region & $4.93 *$ & $4.57 *$ \\
\hline Regression proportion & $15.94 * * *$ & $6.93 *$ \\
\hline \multicolumn{3}{|l|}{ Region 4} \\
\hline First-pass reading times & 2.17 & 2.73 \\
\hline Go-past reading times & $7.58 * *$ & $5.49 *$ \\
\hline Total time in region & $10.43 * *$ & $9.03 * *$ \\
\hline Regression proportion & 2.01 & $<1$ \\
\hline \multicolumn{3}{|l|}{ Region 5} \\
\hline First-pass reading times & 1.75 & 1.55 \\
\hline Go-past reading times & $21.39 * * *$ & $25.92 * * *$ \\
\hline Total time in region & $32.75 * * *$ & $40.04 * * *$ \\
\hline Regression proportion & $9.92 * *$ & $6.65 *$ \\
\hline \multicolumn{3}{|l|}{ Region 6} \\
\hline First-pass reading times & $<1$ & $<1$ \\
\hline Go-past reading times & $<1$ & $<1$ \\
\hline Total time in region & $<1$ & $<1$ \\
\hline Regression proportion & & \\
\hline
\end{tabular}

${ }^{a}$ First-pass regression proportion.

$* p<.05 . * * p<.01$. $* * * p<.001$.

is, low attachment sentences were read more slowly in this last region than high attachment sentences. The results from this final region do not lend themselves to clear interpretation.

The overall pattern of results for the Chinese learners of English was similar to that which was obtained for the English NSs. For this NNS group, high attachment sentences also had longer total sentence RTs than low attachment sentences, $F 1$ $(1,28)=35.31, p<.001, F 2(1,22)=28.60, p<.001$. Under the per-region measures, there were unexpected differences in Regions 2 and 3. Region 2 showed 
a greater first-pass regression proportion for low attachment sentences, $F 1(1,28)=$ $6.51, p<.05, F 2(1,22)=23.73, p<.001$. However, in Region 3 , the region immediately preceding the time adverbial, there was a greater proportion of firstpass regressions in high attachment sentences, $F 1(1,28)=15.93, p<.001, F 2$ $(1,22)=6.93, p<.05$. In this region, first-pass RTs were also faster for low attachment sentences, $F 1(1,28)=4.93, p<.05, F 2(1,22)=6.12, p<.05$ (see the Discussion Section). The results at and immediately after the critical region, however, were comparable to those of the NS group. Specifically, the NNSs had longer go-past and total RTs for high attachment sentences at the critical region, Region 4: go-past RT, $F 1(1,28)=7.58, p<.01, F 2(1,22)=5.49, p<.05$; total $\mathrm{RT}, F 1(1,28)=10.43, p<.01, F 2(1,22)=9.03, p<.01$, and in the immediately following region, Region 5: go-past RT, $F 1(1,28)=21.39, p<.001, F 2(1,22)$ $=25.92, p<.001 ;$ total RT, $F 1(1,28)=32.75, p<.001, F 2(1,22)=40.04$, $p<.001$. They also had a greater proportion of first-pass regressions for high attachment sentences in Region 5, $F 1(1,28)=9.92, p<.01, F 2(1,22)=6.65$, $p<.05$. Finally, NNSs showed longer total RTs in Region 3 of high attachment sentences compared to low attachment sentences, $F 1(1,28)=4.93, p<.05, F 2$ $(1,22)=4.57, p<.05$. Again, this difference is likely due to "tense checking" regressive eye movements in high attachment sentences.

In sum, both the English NSs and the Chinese learners of English showed a clear low attachment bias on sentences containing time adverbials in ambiguous structural positions. The reading patterns for the groups were quite similar on these sentence types.

$N P$ versus sentence coordination. In the statistical analyses for coordination ambiguity sentences, sentence type (unambiguous, ambiguous) was a repeated measure. Total sentence RTs for this sentence type are presented in Table 1 for NSs, and in Table 2 for NNSs. The mean first-pass RTs, go-past RTs, total RTs, and first-pass regression proportions for these sentences are presented (by condition and region) in Table 11 for NSs, and in Table 12 for NNSs. The results of the ANOVAs for each of these measures in each region are presented in Table 13 for NSs, and in Table 14 for NNSs.

For the English NSs, longer total sentence RTs were found for temporarily ambiguous coordination sentences (i.e., sentences without the clause-separating comma) than for their unambiguous counterparts, $F 1(1,28)=8.44, p<.01$, $F 2(1,22)=10.89, p<.01$. In the per-region measures, this group showed disrupted reading for unambiguous sentences in Region 2, which contained the disambiguating comma in this sentence type. This was indicated by longer gopast RTs, $F 1(1,28)=14.32, p<.01, F 2(1,22)=16.81, p<.001$, and a greater proportion of first-pass regressions, $F 1(1,28)=12.28, p<.01, F 2(1$, $22)=17.51, p<.001$, on unambiguous sentences. This effect could reflect the processing costs associated with closing a clause (i.e., a wrap-up effect; Hill \& Murray, 2000; Warren, White, \& Reichle, 2009), or (given that there is clearly additional material to the right of the comma) with initiating a new clause, or both. More importantly, there were longer go-past and total RTs in Region 3 for ambiguous sentences: go-past RT, $F 1(1,28)=7.14, p<.05, F 2(1,22)=4.94$, 
Table 11. Native speakers means (standard deviations) for noun phrase versus sentence coordination sentences

\begin{tabular}{|c|c|c|c|c|c|}
\hline & \multicolumn{5}{|c|}{ Region } \\
\hline & 1 & 2 & 3 & 4 & 5 \\
\hline & \multicolumn{5}{|c|}{ Unambiguous } \\
\hline & $\begin{array}{l}\text { The nurse } \\
\text { examined }\end{array}$ & $\begin{array}{l}\text { the } \\
\text { mother, }\end{array}$ & $\begin{array}{l}\text { and the } \\
\text { child }\end{array}$ & $\begin{array}{l}\text { played } \\
\text { quietly }\end{array}$ & $\begin{array}{l}\text { in the } \\
\text { corner. }\end{array}$ \\
\hline & \multicolumn{5}{|c|}{ Ambiguous } \\
\hline & $\begin{array}{l}\text { The nurse } \\
\text { examined }\end{array}$ & $\begin{array}{l}\text { the } \\
\text { mother, }\end{array}$ & $\begin{array}{l}\text { and the } \\
\text { child }\end{array}$ & $\begin{array}{l}\text { played } \\
\text { quietly }\end{array}$ & $\begin{array}{l}\text { in the } \\
\text { corner. }\end{array}$ \\
\hline \multicolumn{6}{|c|}{ First-pass reading times } \\
\hline Unambiguous & $672(158)$ & $401(105)$ & $474(122)$ & $519(117)$ & $477(136)$ \\
\hline Ambiguous & $675(169)$ & $377(82)$ & $496(117)$ & $562(135)$ & $494(161)$ \\
\hline \multicolumn{6}{|c|}{ Go-past reading times } \\
\hline Unambiguous & & $544(188)$ & $520(146)$ & $576(127)$ & $457(143)$ \\
\hline Ambiguous & & $447(135)$ & $563(144)$ & $760(285)$ & $488(179)$ \\
\hline \multicolumn{6}{|c|}{ Total time in region } \\
\hline Unambiguous & $922(238)$ & $558(167)$ & $643(184)$ & $678(176)$ & $558(162)$ \\
\hline Ambiguous & $895(265)$ & $552(203)$ & $735(228)$ & $825(245)$ & $598(176)$ \\
\hline \multicolumn{6}{|c|}{ First-pass regression proportion } \\
\hline Unambiguous & & $.20(.18)$ & $.06(.07)$ & $.09(.10)$ & \\
\hline Ambiguous & & $.09(.11)$ & $.08(.10)$ & $.18(.14)$ & \\
\hline
\end{tabular}

$p<.05$; total RT, $F 1(1,28)=15.62, p<.01, F 2(1,22)=15.39, p<.01$. This effect plausibly reflects the partial reanalysis of an initial conjoined NP interpretation of the sentence, or difficulty joining two constituents together (see the Discussion section below). At the critical region containing the second clause verb, Region 4, ambiguous sentences incurred longer first-pass, go-past, and total RTs, and a greater proportion of first-pass regressions than unambiguous sentences: first-pass RT, $F 1(1,28)=4.51, p<.05, F 2(1,22)=5.65, p<.05$; go-past RT, $F 1(1,28)=$ $17.79, p<.001, F 2(1,22)=26.21, p<.001$; total RT, $F 1(1,28)=22.04, p<$ $.001, F 2(1,22)=26.58, p<.001$; first-pass regression proportion, $F 1(1,28)=$ $13.12, p<.01, F 2=15.28, p<.01$. These RT slowdowns indicate processing difficulty when a conjoined NP analysis is disconfirmed by the second clause verb in temporarily ambiguous coordination sentences. Finally, there were also longer total RTs for ambiguous sentences in the final region, Region $5, F 1(1,28)=4.68$, $p<.05, F 2(1,22)=6.27, p<.05$, a result that likely reflects the spill-over of processing difficulty from the preceding region.

The NNSs showed very similar reading patterns on these coordination sentences. For this group, longer total sentence RTs were also obtained for temporarily ambiguous coordination sentences, $F 1(1,28)=7.66, p<.01, F 2(1,22)=$ 
Table 12. Nonnative speaker means (standard deviations) for noun phrase versus sentence coordination sentences

\begin{tabular}{|c|c|c|c|c|c|}
\hline & \multicolumn{5}{|c|}{ Region } \\
\hline & 1 & 2 & 3 & 4 & 5 \\
\hline & \multicolumn{5}{|c|}{ Unambiguous } \\
\hline & $\begin{array}{l}\text { The nurse } \\
\text { examined }\end{array}$ & $\begin{array}{l}\text { the } \\
\text { mother, }\end{array}$ & $\begin{array}{l}\text { and the } \\
\text { child }\end{array}$ & $\begin{array}{l}\text { played } \\
\text { quietly }\end{array}$ & $\begin{array}{l}\text { in the } \\
\text { corner. }\end{array}$ \\
\hline & \multicolumn{5}{|c|}{ Ambiguous } \\
\hline & $\begin{array}{l}\text { The nurse } \\
\text { examined }\end{array}$ & $\begin{array}{l}\text { the } \\
\text { mother, }\end{array}$ & $\begin{array}{l}\text { and the } \\
\text { child }\end{array}$ & $\begin{array}{l}\text { played } \\
\text { quietly }\end{array}$ & $\begin{array}{l}\text { in the } \\
\text { corner. }\end{array}$ \\
\hline \multicolumn{6}{|c|}{ First-pass reading times } \\
\hline Unambiguous & $794(180)$ & $565(171)$ & $616(140)$ & 709 (159) & $671(201)$ \\
\hline Ambiguous & $796(227)$ & $533(186)$ & $735(179)$ & $740(144)$ & $647(165)$ \\
\hline \multicolumn{6}{|c|}{ Go-past reading times } \\
\hline Unambiguous & & $702(275)$ & $776(213)$ & $862(185)$ & $651(166)$ \\
\hline Ambiguous & & $637(240)$ & $881(267)$ & $915(203)$ & $684(172)$ \\
\hline \multicolumn{6}{|c|}{ Total time in region } \\
\hline Unambiguous & $1048(262)$ & $778(233)$ & $884(229)$ & 934 (179) & $770(256)$ \\
\hline Ambiguous & $1069(321)$ & $784(279)$ & $1036(250)$ & $1032(207)$ & $774(208)$ \\
\hline \multicolumn{6}{|c|}{ First-pass regression proportion } \\
\hline Unambiguous & & $.15(.14)$ & $.14(.16)$ & $.14(.12)$ & \\
\hline Ambiguous & & $.12(.11)$ & $.14(.10)$ & $.16(.12)$ & \\
\hline
\end{tabular}

19.85, $p<.001$. In the per-region measures, like the NS control group, these NNSs also showed a slowdown at the comma in unambiguous sentences, as indicated by longer go-past RTs in Region $2, F 1(1,28)=5.18, p<.05, F 2$ $(1,22)=6.78$. In Region 3, ambiguous sentences had longer first-pass, go-past, and total RTs, first-pass: $F 1(1,28)=20.85, p<.001, F 2(1,22)=20.03$, $p<.001$; go-past RT, $F 1(1,28)=16.64, p<.001, F 2(1,22)=6.28, p<.05$; total RT, $F 1(1,28)=23.55, p<.001, F 2(1,22)=15.79, p<.001$, a result that again suggests processing difficulty at the structurally ambiguous NP. At the critical region containing the second clause verb, Region 4, total RTs were longer for ambiguous sentences than for their unambiguous counterparts, $F 1(1,28)=$ $8.94, p<.01, F 2(1,22)=15.39, p<.01$, indicating processing difficulty when a coordinated-NP interpretation of the sentence is disconfirmed. These reading patterns thus suggest a conjoined-NP bias for both NSs and NNSs.

\section{DISCUSSION}

In this study, both English NSs and highly proficient Chinese learners of English showed interpretive biases on all three of the sentence types that were tested. In 
Table 13. Analysis of variance results for noun phrase versus sentence coordination sentences in native speakers

\begin{tabular}{lcc}
\hline & \multicolumn{2}{c}{ Conjoin Preference } \\
\cline { 2 - 3 } & $F 1(1,28)$ & $F 2(1,22)$ \\
\hline Region 1 & & \\
First-pass reading times & $<1$ & $<1$ \\
Go-past reading times & & \\
Total time in region & $<1$ & \\
Regression proportion & & \\
Region 2 & & \\
First-pass reading times & 3.08 & 2.18 \\
Go-past reading times & $14.32^{* *}$ & $16.81^{* * *}$ \\
Total time in region & $<1$ & $<1$ \\
Regression proportion & $12.28^{* *}$ & $17.51^{* * *}$ \\
Region 3 & & \\
First-pass reading times & $4.59^{*}$ & 2.11 \\
Go-past reading times & $7.14^{*}$ & $4.94^{*}$ \\
Total time in region & $15.62^{* * *}$ & $15.39^{* *}$ \\
Regression proportion & 1.97 & 3.92 \\
Region 4 & & \\
First-pass reading times & $4.51^{*}$ & $5.65^{*}$ \\
Go-past reading times & $17.79^{* * *}$ & $26.21^{* * *}$ \\
Total time in region & $22.04^{* * *}$ & $26.58^{* * *}$ \\
Regression proportion & $13.12^{* *}$ & $15.28^{* *}$ \\
Region 5 & & \\
First-pass reading times & $<1$ & 1.02 \\
Go-past reading times & 2.37 & 3.53 \\
Total time in region & $4.68^{*}$ & $6.27^{*}$ \\
Regression proportion & & \\
\hline \hline
\end{tabular}

${ }^{a}$ First-pass regression proportion.

$* p<.05 . * * p<.01 . * * * p<.001$.

the RC attachment sentences, the direction of the bias was different for the two groups. Consistent with the results often obtained in studies of RC attachment in L1 English (Carreiras \& Clifton, 1999; Cuetos \& Mitchell, 1988; Frazier \& Clifton, 1996), the NSs showed a low attachment bias. As discussed above, this preference has been explained in terms of recency, a locality principle that guides the parser to attach new elements to the most recently processed constituent (Gibson et al., 1996). The Chinese learners of English, however, revealed a high $\mathrm{RC}$ attachment bias. Again, as detailed above, this preference has been accounted for with reference to the locality principle of predicate proximity, which biases the parser to attach modifiers to argument positions (Gibson et al., 1996). Thus, the results of the present study indicate RC attachment in accordance with both of the structure-based parsing principles that are attested in the processing of structurally ambiguous NP modifiers, with NSs using recency and NNSs using 
Table 14. Analysis of variance results for noun phrase versus sentence coordination sentences in nonnative speakers

\begin{tabular}{lcc}
\hline \hline & \multicolumn{2}{c}{ Conjoin Preference } \\
\cline { 2 - 3 } & $F 1(1,28)$ & $F 2(1,22)$ \\
\hline Region 1 & & \\
First-pass reading times & $<1$ & $<1$ \\
Go-past reading times & & \\
Total time in region & $<1$ & 1.36 \\
Regression proportion & & \\
Region 2 & & \\
First-pass reading times & 2.23 & 1.86 \\
Go-past reading times & $5.18^{*}$ & $6.78^{*}$ \\
Total time in region & $<1$ & $<1$ \\
Regression proportion & 1.01 & 2.46 \\
Region 3 & & \\
First-pass reading times & $20.85^{* * *}$ & $20.03^{* * *}$ \\
Go-past reading times & $16.64^{* * *}$ & $6.28^{*}$ \\
Total time in region & $23.55^{* * *}$ & $15.79^{* * *}$ \\
Regression proportion & $<1$ & $<1$ \\
Region 4 & & \\
First-pass reading times & 1.14 & $4.47^{*}$ \\
Go-past reading times & 2.09 & 2.53 \\
Total time in region & $8.94^{* *}$ & $15.39^{* *}$ \\
Regression proportion & $<1$ & $<1$ \\
Region 5 & & $<1$ \\
First-pass reading times & 1.01 & 1.50 \\
Go-past reading times & 2.17 & $<1$ \\
Total time in region & $<1$ & \\
Regression proportion & & \\
\hline \hline
\end{tabular}

${ }^{a}$ First-pass regression proportion.

$* p<.05 . * * p<.01 . * * * p<.001$.

predicate proximity. In the adverb attachment ambiguity sentences, NSs and NNSs revealed a low attachment bias, which is a result consistent with the cross-linguistic preference for attaching VP modifiers locally or in accordance with the recency principle. Both participant groups also showed a bias toward a conjoined-NP interpretation in the coordination ambiguity sentences, a default interpretation that is consistent with the minimal attachment principle (Frazier, 1987b). This set of results thus suggests that both L1 and L2 sentence processing is guided (at least in part) by structure-based biases in the computation of abstract relationships among syntactic constituents, although the specific parameters of (some of) these biases might differ for NSs and NNSs. To the extent that these biases can be taken as indications of the depth and detail of syntactic processing, these results further suggest that both NSs and NNSs establish rich structural representations during online sentence comprehension. 
Before discussing additional issues related to each sentence type of interest, it is necessary to address a couple of statistically reliable differences that were not anticipated. First, in the RC attachment sentences, NSs had significantly longer go-past RTs for high attachment sentences in Region 2 (e.g., . . of the actress), the region just prior to the critical region of the RC (e.g., .. . who shot herself/himself). One possibility is that this effect is due to parafoveal preview, which by some estimates, may extend rightward up to fifteen characters (Rayner \& Pollatsek, 1989). It is controversial, however, what kind of information can be extracted parafoveally. By some accounts, a parafoveal word is unlikely to be identified if it is further than seven- to eight-letter spaces to the right of fixation (McConkie \& Rayner, 1975; Rayner 1998; Rayner, Well, Pollatsek, \& Bertera, 1982), and in many of our sentence materials, the disambiguating reflexive was further than that from the words in Region 2, where this RT difference is apparent. In contrast, much is yet unknown about precisely how much information one needs to identify a word, especially words like herself and himself, which (particularly in the course of an experiment such as this) readers encounter rather frequently. Thus, although it seems unlikely that parafoveal information could be used to evaluate the reflexiveantecedent match/mismatch crucial to these $\mathrm{RC}$ attachment sentences, it is perhaps not impossible (for more on the limits of parafoveal information, see, e.g., Balota, Pollatsek, \& Rayner, 1985; Rayner \& Pollatsek, 1989; but see also Kennedy, Murray, \& Boissiere, 2004). ${ }^{3}$ Second, in the adverb attachment sentences, NNSs showed significantly longer first-pass RTs on low attachment sentences in Region 3 (... he phoned), the region just prior to the critical region of the time adverbial (... yesterday/tomorrow). This difference is in the opposite direction of the other statistically reliable differences found for this sentence type, all of which indicate processing difficulty for high adverb attachment sentences, so it is tempting to attribute this effect to chance. However, an alternative explanation for this result might again appeal to parafoveal preview effects. It is sometimes the case that "early" reading measures such as first-pass RT (and first fixation duration) are faster in regions that induce relatively large numbers of first-pass regressions (Altmann, Garnham, \& Dennis, 1992; Rayner \& Sereno, 1994; Staub, 2010). There was a greater probability of a first-pass regression for high attachment sentences in Region 3. Thus, the shorter first-pass RTs in Region 3 of these sentences may be a consequence of a large number of regressive eye movements when tense-adverbial mismatches were detected parafoveally.

With respect to the coordination ambiguity sentences, another finding worth some discussion is that both NSs and NNSs showed processing difficulty at the temporarily ambiguous NP and at the disambiguating region, the verb in the second clause. This slowdown at the ambiguous NP was not found in Hoeks et al. (2006), the only other eye-tracking study to investigate the processing of these sentence types. The processing difficulty at the region of the verb in the second clause was entirely expected and can be taken to index reanalysis of the sentence from a single-clause interpretation to a dual-clause interpretation. This reanalysis is forced by verbal information that clearly indicates the necessity of building a new clause. The processing difficulty at the temporarily ambiguous NP might also be interpreted in terms of reanalysis. Specifically, early reanalysis of a coordinated NP interpretation could be triggered by information indicating that 
the word following this NP has form properties consistent with a verb. The verb in the second clause always immediately followed the structurally ambiguous $\mathrm{NP}$ and was either a high-frequency irregular past tense form or a regular past tense form. Another possible explanation for the slowing at the second NP is that the process of conjoining two NPs into a single argument is itself complex. If the first NP (the mother as in (3b)) has already been assigned a thematic role, the appearance of a second NP (the child) will require some adjustment to the on-going interpretation of the sentence, even if a default minimal attachment parse is computed. In contrast, the same NP in the comma condition (3a) can only be analyzed as a simple NP, and simple NPs are likely to be easier to process.

With regard to the RC attachment sentences, the most important result is that both NSs and NNSs revealed total RT differences at the critical region of the RC, indicating a low attachment bias for NSs and a high attachment bias for NNSs. These findings are particularly interesting in light of the mixed findings for $\mathrm{RC}$ attachment in the L2 processing literature and, more specifically, in light of the failure to obtain comparable differences (for genitive construction sentences) in studies taken to support the SSH (Dussias, 2003; Felser et al., 2003; Fernández, 2002, 2003; Frenck-Mestre, 1999, 2002; Papadopoulou \& Clahsen, 2003). As mentioned in the Introduction, task sensitivity might play a role here. That is, in order to detect this often subtle RC attachment effect, it may be necessary to use a potentially very sensitive methodology like eye tracking. Alternatively (or in addition to task sensitivity), the location of the complex NP in our RC sentences may have affected attachment. In order to comprehend these sentences, readers must develop and maintain a detailed representation of the complex subject NP such that the relevant components of this phrase can be used for subsequent processing operations. For instance, these sentences require distinct structural features to be encoded/maintained for NP1 and NP2 in order to understand who did what to whom in the main proposition of the sentence. This distinguishes the sentences in this study from those used in previous L2 studies, which have tended to be sentences like the following: The dean liked the secretary of the professors who was/were reading (Felser et al., 2003). In this sentence, the complete propositional structure for the main clause can be computed at NP1 (the secretary), with the remaining information simply augmenting this clause. Therefore, it could be argued that the RC attachment sentences in the present study allow for a clearer and more effective test of whether NNSs compute the detailed hierarchical structure necessary for structure-based parsing principles to apply.

These findings are also interesting in light of the similarly mixed results in L1 English studies of RC attachment generally, and in particular, of sentences disambiguated by antecedent-reflexive gender agreement. In studies examining this specific sentence type, Frazier and Clifton (1996) showed a low attachment bias, whereas Traxler et al. (1998) found no clear evidence for either a high or low attachment bias. The disparity between the findings of the present study and those of Traxler et al. (1998) may be due to a variety of methodological differences between their study and ours. One difference is that Traxler et al. (1998) tested both temporarily ambiguous sentences (e.g., The son of the actress who shot herself/himself....) and globally ambiguous sentences (e.g., The daughter 
the actress who shot herself. . . .), whereas the present study tested only the former sentence type. It is possible that forcing participants to make structural determinations on all sentences of this type (and throughout the experiment as a whole) yielded more consistent preferences. The influence of such task effects is all the more plausible in light of the generally weak and inconsistent results obtained for English RC attachment sentences. Given the inconsistency of RC attachment effects across published reports, it is perhaps not surprising that we found an effect, whereas others have not.

It is also interesting that the direction of the bias on these sentences was different for NSs and NNSs. What accounts for the high attachment preference shown by the NNSs? There are a number of potential explanations. In line with the analysis of this sentence type put forward under the SSH, this could be explained in terms of a difference in the relative weighting of the locality principles of recency and predicate proximity by English NSs and this particular group of NNSs. However, why would these Chinese learners of English weight predicate proximity over recency? Gibson et al. (1996) propose that the strength of predicate proximity in a given language relates to the average distance between predicate heads (i.e., verbs) and their arguments. In languages with relatively free word orders like Spanish (which, in addition to its canonical subject-verb-object (SVO) order, allows for word orders such as VOS), this distance is relatively large, and greater initial activation of the predicate is required in order to support attachment over greater distances. In such languages, predicate proximity is stronger. In contrast, in languages with relatively rigid word orders like English, the average distance between predicate heads and their arguments tends to be shorter, and predicate proximity is weaker. Although Chinese regularly adheres to an SVO word order, at least under some analyses (see, e.g., Soh, 1998), overt object scrambling (or movement of the object from its canonical position) is available in this language in a way comparable to that which is evinced in German, a language that has been taken to have a relatively free word order and that, consistent with Gibson et al.'s (1996) hypothesis, reveals a high RC attachment bias in accordance with predicate proximity (Hemforth, Konieczny, \& Scheepers, 2000; for discussion, see Felser et al., 2003). Therefore, it is possible that predicate proximity is also assigned greater weight in Chinese, and that this parameter setting influences the L2 English processing of RC attachment sentences by Chinese learners. It is interesting that, however, the results for L1 Chinese RC attachment sentences are mixed; there is evidence for both a high attachment preference (Cai, 2009) and a low attachment preference (Shen, 2006), making it difficult to conclude that the predicate proximity strategy is transferred from L1 Chinese to L2 English processing. Ultimately, if it is the case, as C\&F argue, that Gibson's locality principles drive interpretive biases in the genitive construction of RC attachment sentences, then, although it is unclear why the Chinese-English NNSs showed a high attachment bias, the fact that they showed a bias at all indicates that they are capable of using phrase structure-based parsing principles.

It is similarly difficult to evaluate other models of L2 sentence processing that take L1 biases into account. For instance, cross-linguistic differences in $\mathrm{RC}$ attachment preferences have been explained in terms of the tuning hypothesis (Mitchell \& Cuetos, 1991), which essentially states that these structural 
ambiguities are resolved according to the relative frequencies of previously encountered alternative disambiguations. Under this theory, the low attachment bias found for English NSs would be due to their exposure to more RC sentences involving low attachment resolutions, whereas the high attachment bias for Chinese learners of English would be due to their exposure to more high attachment resolutions on analogous sentences in L1 Chinese. In other words, these learners may not have overcome their L1 "tuning" with respect to this sentence type. Dussias (2001) has appealed to this tuning hypothesis in order to account for changes in attachment preferences (in both the L1 and L2) for Spanish learners of English with increasing L2 English exposure/proficiency (for similar findings, see Dussias \& Sagarra, 2007). However, given that it is unclear what the L1 (Chinese) preference is, it is difficult to assess whether there is an influence of L1 tuning on their processing of L2 English.

Another transfer-based account for these findings might appeal not to the carryover of a specific RC attachment strategy, but rather to the application (and occasional misapplication) of an L1-based preference for linking reflexive anaphors to sentential subjects. It is well documented that there is a strong subject orientation for the (long-distance) reflexive ziji in Chinese (Cole, Hermon, \& Sung, 1990; Cole \& Sung, 1994). If this subject orientation were transferred in the processing of the RC attachment sentences in the present study, the apparent preference for NP1 attachment might in fact reflect a preference for linking the (disambiguating) reflexive in the RC with the subject of the sentence (or rather, the head NP within the complex subject NP). However, there is some evidence suggesting that this subject orientation property resists transfer. In a study investigating the L2 acquisition of long-distance Chinese reflexives by English and Japanese learners, both groups had difficulty acquiring the subject orientation of $z i j i$, despite the fact that the same property applies to the Japanese reflexive zibun (Yuan, 1998). Further, identification of NP1 as the head of the subject NP requires some way of distinguishing the roles played by NP1 and NP2, such as computing and keeping track of the syntactic positions that they occupy.

Finally, one might also attempt to explain the difference in the direction of this $\mathrm{RC}$ attachment bias in terms of more global processing differences between the NSs and NNSs. For instance, another account of cross-linguistic differences in $\mathrm{RC}$ attachment biases is the implicit prosody hypothesis (IPH), which posits that even in silent reading, readers project a default prosodic contour (Fodor, 1998, 2002; Schafer, Carter, Clifton, \& Frazier, 1996). On this view, in RC structures like these, the length of the RC will affect whether readers impose a prosodic break between it and the complex subject NP, which in turn affects the attachment decision (with low attachment preferred if there is no break). It may be the case that the implicit prosodic contour that these NNSs projected onto the English RC attachment sentences differed from that of the NSs. However, in the absence of L2 production data for these sentence types, it is unclear how to determine whether this explanation is correct. One could also appeal to failed pragmatic processing by the Chinese NNSs in order to explain this RC attachment difference. Specifically, the different biases shown by the NSs and NNSs might be accounted for by positing a universal preference to attach (or associate) RC modifiers to the higher NP, as proposed under construal (Frazier \& Clifton, 1996). For English NSs, this 
preference might be counteracted by the availability of expressing possession with 's (or with the so-called Saxon genitive). That is, English NSs would apply Gricean logic (specifically, the Maxim of Manner, be clear, Grice, 1975) to determine that if high attachment were intended, the speaker/writer would have used 's in the complex NP (e.g., the actress' son; for more on this account, see Frazier \& Clifton, 1996). If the Chinese learners of English were unable to process the pragmatic implications of the Norman genitive (e.g., The son of the actress) to a comparable extent, they could have simply applied the default interpretation (associate the RC with the higher NP) to these sentence types. It is again important to note that such a "default" association requires the computation of a complex NP structure of some depth: a "high association" strategy will only work if the two NPs within the subject NP are distinguishable in terms of their structural position.

In contrast to the results for RC attachment sentences, both NSs and NNSs showed interpretive biases in the same direction for adverb attachment sentences. Specifically, consistent with previous eye-tracking results on these sentence types in L1 English (Altmann et al., 1998), both subject groups showed a clear preference for attaching the AdvP to the local VP, or a low attachment bias. With reference to Gibson's locality principles, we interpret these findings to indicate that both NSs and NNSs are able to apply recency in the online attachment of VP modifiers. Hence, on this account, both NSs and NNSs are employing a structurebased processing strategy in the interpretation of these sentences. An alternative explanation for these results might appeal to construal theory (Frazier \& Clifton, 1996, 1997). Within this framework, nonprimary phrases (again, constituents that do not directly relate to the main predicate and its arguments) are preferentially associated with the current thematic processing domain. (Recall that $\mathrm{C} \& \mathrm{~F}$ draw on this theory in order to explain L2 comprehenders' clear preference for low attachment in RC attachment sentences in which the relevant NPs are linked by with.) Adverb phrases are nonprimary, and they would preferentially associate into the "extended maximal projection" of the most recent theta assigner, in this case, the domain established by the nearest theta-assigning verb (Frazier \& Clifton, 1996, 1997). Does this mean that structure-based biases are not in play in the processing of these sentences? Ultimately, this depends on one's definition of "structure-based."

It is important to note that construal does not provide a comparable competing explanation for the processing of coordination ambiguity sentences. In fact, even under construal theory, the attachment of such phrases into developing structural representations is governed by principles such as minimal attachment (Frazier \& Clifton, 1996, 1997), that is, by phrase-structure-based parsing principles that the SSH holds are inoperative in L2 processing. However, both NSs and NNSs exhibited reading patterns consistent with an initial analysis of these sentences according to minimal attachment. Specifically, both participant groups indicated a default conjoined-NP interpretation for temporarily ambiguous coordination ambiguity sentences. Therefore, in terms of explaining away the implications of the present set of results for hierarchical structural processing during L2 sentence comprehension, construal theory gives with one hand and takes with the other. 
In sum, although it may be possible to account for one or the other of the results reported in this experiment by appealing to plausibility, (lexico-)semantics, or some other nonsyntactic source of information, it is difficult to account for the complete pattern of results without positing at least some role for structure-based parsing biases in L2 sentence processing. Assuming that these biases can be taken to indicate rich structural processing, it would appear therefore that both NSs and NNSs compute syntactic structures of comparable depth and detail during online sentence comprehension. The overlap between syntactic processing in native and nonnative languages is also underscored by the general RT patterns for NSs and NNSs on the sentence types tested in this experiment. For instance, both NSs and NNSs appeared to resolve misparses with well-targeted regressive fixations to regions that were particularly relevant to recovering the correct interpretation. Consider, for instance, the reading pattern of NNSs on RC attachment sentences. When the reflexive indicated low attachment, there were inflated total RTs (which include fixations after regressive eye movements) at the RC and at the apparently preferred attachment site, the high (nonlocal) noun. Similarly, with adverb attachment sentences, when the adverb indicated high attachment, there were inflated total RTs at the adverb and at the local VP, which again was the apparently preferred attachment site. In order for such efficient reanalysis/recovery to occur, it seems necessary to generate and maintain structured representations of sentences in real time. It is important to note that only eye tracking can provide such sensitive indications of reanalysis, and thus it seems to be a methodology particularly well suited to the examination of structural computation during online L2 sentence comprehension.

A final point to consider is the extent to which detailed L2 structural processing requires superior L2 proficiency. That is, one possibility is that the NNSs in the present experiment were of such high proficiency that they could access a greater range of knowledge sources during online sentence processing than NNSs tested in many previous experiments. C\&F (2006a) note that shallow L2 processing may be due to deficient and/or deviant (implicit) L2 grammatical knowledge. ${ }^{4}$ However, if it is the case that our subjects are "too proficient," then this would suggest that shallow structure computation is a developmental stage, not a characteristic of L2 processing generally.

\section{Directions for further research}

The results of this study present a challenge to the SSH. In particular, they cast doubt on the assertion that L2 sentence comprehension is characterized by shallow structural processing. However, more research is required in order to test this claim comprehensively. The present study tested this prediction by looking at the L2 English processing of three of temporarily ambiguous structural configurations. Of course, further examinations into a range of such structures in various L2s (by learners from different L1 backgrounds) are necessary. In light of the subtlety of the findings for RC attachment sentences in the present study and in RC attachment studies in general, it is perhaps best not to overemphasize (and overrepresent) examinations of this sentence type. Although indications of an online bias in $\mathrm{RC}$ attachment sentences can be interesting (as in the present study), null results 
(even in the context of significant findings) cannot be taken to support any firm conclusion given the generally mixed findings for this sentence type. This seems to be particularly true for studies of L2 English, a language that has produced weak and inconsistent indications of an online attachment bias.

With respect to examining different languages, it would be especially interesting to test the predictions of the SSH with studies of L2 processing in head-final languages. After all, this research hypothesis appears to rely rather heavily on verb information, specifically verb subcategorization and argument structure information, in order to explain the mechanisms that underlie online L2 sentence comprehension. In many ways, the SSH seems to posit a very much head-driven model of parsing (analogous to Pritchett, 1991). Such a model will be able to explain a great number of phenomena in the L2 parsing of English and other head-initial languages, in which verb information comes early. However, in headfinal languages (e.g., Japanese) verb information is not available until the end of the clause/sentence. There are nevertheless a number of studies indicating that during the parsing of head-final sentences, rich structural decisions are generated incrementally and well before verbal information becomes available (Inoue \& Fodor, 1995; Kamide, 2006; Miyamoto, 2002; Witzel \& Witzel, 2011). Indications of comparable incremental processing in the L2 parsing of head-final languages would pose serious problems for the SSH.

\section{APPENDIX A: RC ITEMS}

The son of the actress who shot herself/himself on the set was under investigation. The brother of the bride who embarrassed herself/himself at the wedding felt ashamed. The uncle of the waitress who hurt herself/himself was shocked by the accident. The son of the lady who politely introduced herself/himself was popular at the party. The brother of the schoolgirl who burned herself/himself was usually very careful. The grandfather of the woman who killed herself/himself last summer had been to prison. The grandma of the fireman who criticized himself/herself far too often was anxious. The aunt of the schoolboy who hurt himself/herself was concerned about the injury. The daughter of the man who complimented himself/herself in public was beautiful. The sister of the salesman who made a fool of himself/herself at work was very angry. The daughter of the actor who hated himself/herself for failing always seemed unhappy. The sister of the prince who injured himself/herself falling off a roof was still sad. The son of the princess who scratched herself/himself in public was awfully embarrassed. The brother of the ballerina who found herself/himself in a lot of trouble phoned home. The nephew of the maid who cut herself/himself with the knife called the doctor. The grandfather of the policewoman who treated herself/himself so badly was troubled. The nephew of the queen who praised herself/himself all the time was very rude. The uncle of the girl who prepared herself/himself for the race was a great athlete. The grandma of the policeman who educated himself/herself at night became a teacher. The niece of the fisherman who got himself/herself a sailboat learned to sail.

The daughter of the king who devoted himself/herself to the kingdom was never emotional. The sister of the boy who taught himself/herself advanced mathematics was very smart. The aunt of the waiter who trained himself/herself to cook wanted to own a restaurant. The niece of the butler who scolded himself/herself for losing the key was very upset. 


\section{APPENDIX B: ADVERB ATTACHMENT ITEMS}

Anne will serve the apples she picked yesterday/tomorrow, but she won't serve the plums.

Robert will meet the friend he phoned yesterday/tomorrow, but he doesn't want to.

David caught the fish he will cook tomorrow/yesterday, but it is not his favorite kind.

Sue insulted the candidate she will debate tomorrow/yesterday, but she wishes she hadn't. Jane prepared the lecture she will give next/last week, but still needs to review it. Joseph brewed the beer he will serve next/last week, but it is not very tasty.

Tom will plant the tree he bought last/next week, but he isn't sure where to put it. Lisa will change the plans she made last/next week, but she won't cancel any of them. Jeff planned the party he will hold next/last month, but he hasn't sent invitations. Dan wrote the speech he will deliver next/last month, but he hasn't practiced it yet. Paul will marry the woman he just met last/next month, but the wedding will be small. Amy will visit the man she worked with last/next month, but she is nervous about it. Linda will wear the sweater she washed yesterday/tomorrow, but she won't wear her skirt. James will fix the car he drove yesterday/tomorrow, but he will need some help. Mary called the applicant she will interview tomorrow/yesterday, but there was no answer. Mike watered the flower he will sell tomorrow/yesterday, but he forgot to water the bush. Susan bought the wine she will drink next/last week, but she didn't buy any cheese. Chris cleaned the bookcase he will sell next/last week, but it is still very dusty. Mark will answer the email he got last/next week, but he doesn't know what to write. Cathy will burn the wood she gathered last/next week, but she will save some of it. Jim painted the picture he will display next/last month, but he isn't happy with it. John hired the clerk he will promote next/last month, but he fired another employee. Bob will complete the project he started last/next month, but Fred won't finish his. Kim will display the photos she took last/next month, but she won't show all of them.

\section{APPENDIX C: NP VERSUS SENTENCE COORDINATION ITEMS}

The nurse examined the mother(,) and the child played quietly in the corner. The swimmer disappointed her $\operatorname{coach}($,$) and her mother tried to console her.$ The tourist photographed the swimmer(,) and the runner got ready for the race. The little girl fed her pet cat(,) and her dog wanted a can of food, too.

The ranger gave matches to the camper(,) and his friend made a fire by the tent. Jim listened to the pianist(,) and the singer watched the organist at the concert. The audience applauded the guitarist(,) and the band cheered for him very loudly. The producer replaced the actor(,) and the actress quit the movie after the fight. Diane hugged her boyfriend(,) and her friend felt uncomfortable watching them. The woman dressed her baby(,) and her son got his clothes from the dresser. The juggler entertained the children(,) and their parents drank wine at the party. The crowd cheered for the model(,) and the designer took a bow after the show. The teacher praised the girl(,) and her family was proud of her good grades. Bobby yelled at the teacher(,) and the principal asked his parents for a meeting. The woman could not find Bill(,) and his girlfriend became nervous and upset. The customer complained about the waiter(,) and the chef gave him a free dessert. The knight greeted the king(,) and the queen waved to her people at the feast. The police arrested the burglar(,) and his brother phoned a lawyer for help. 
Sam hired the plumber(,) and the carpenter ordered the materials for the house. The actress yelled at the cameraman(,) and the director hurried out of the room. The journalist criticized Nick(,) and Sam called the newspaper to complain. The robber shot the jeweler(,) and the salesman reported the crime to the police. Jenny talked to the reporter(,) and the photographer took pictures of the scene. The witness identified the man(,) and his wife ran away from the police station.

\section{ACKNOWLEDGMENTS}

We are indebted to Stacey Claspill, Leslie Darnell, Katherine Plattner, and Devin St. John for assisting with data collection. This research was supported in part by a University of Arizona SBSRI Small Grant to J. Nicol. Earlier versions of this paper were presented at the CUNY Conference on Human Sentence Processing (Davis, CA, March 2009) and the L2 Processing and Parsing Conference: State of the Science (Lubbock, TX, May 2009).

\section{NOTES}

1. Except for the competition model espoused by MacWhinney and colleagues, these models posit that a rich syntactic structure may be computed in parallel. It is important to emphasize, however, that all of these models claim that semantic interpretation can take place independently of the algorithm-based process of computing rich phrase structure.

2. In line with most eye-tracking studies in which participants answer comprehension questions on a subset of sentences, trials on which there was an incorrect response were not omitted from the data analyses. It is important to note, however, that analyses run both including and excluding these "incorrect trials" did not show different patterns of means or statistical significance.

3. It is also important to note that this difference could not be due to some systematic problem with the items for this sentence type. We have since tested the same materials with NSs using three different self-paced reading tasks: moving-window reading and two versions of maze task reading (Witzel, Witzel, \& Forster, in press). Consistent with the results of the present study, NSs showed a low attachment bias in the processing of RC attachment sentences under each of these tasks. The RT differences between these sentence types obtained at and immediately after the reflexive, but there were no differences at the nonlocal NP.

4. In the original paper in which the SSH was proposed, Clahsen and Felser (2006b) argue that "the observed differences between adult L1 and adult L2 sentence processing cannot be explained in terms of . . incomplete acquisition of the target grammar" (p. 29). However, in their follow-up response paper (Clahsen \& Felser, 2006a), they suggest that "L2 processing is different because of inadequacies of the L2 grammar" (p. 120).

\section{REFERENCES}

Altmann, G. T. M., Garnham, A., \& Dennis, Y. (1992). Avoiding the garden path: Eye movements in context. Journal of Memory and Language, 31, 685-712. 
Altmann, G. T. M., van Nice, K. Y., Garnham, A., \& Henstra, J.-A. (1998). Late closure in context. Journal of Memory and Language, 38, 459-484.

Balota, D. A., Pollatsek, A., \& Rayner, K. (1985). The interaction of contextual constraints and parafoveal visual information in reading. Cognitive Psychology, 17, 364-390.

Barto-Sisamout, K., Nicol, J., Witzel, J., \& Witzel, N. (2009). Transfer effects in bilingual sentence processing. Arizona Working Papers in SLA and Teaching, 16, 1-26.

Bever, T. (1970). The cognitive basis for linguistic structures. In J. R. Hayes (Ed.), Cognition and the development of language (pp. 279-362). New York: Wiley.

Brysbaert, M., \& Mitchell, D. C. (1996). Modifier attachment in sentence processing: Evidence from Dutch. Quarterly Journal of Experimental Psychology, 49A, 664-695.

Cai, Z. (2009). Processing Chinese relative clauses with two attachment sites: Initial resolution and the course of reanalysis. Unpublished manuscript, University of Edinburgh.

Carreiras, M., \& Clifton, C., Jr. (1993). Relative clause interpretation preferences in Spanish and English. Language and Speech, 36, 353-372.

Carreiras, M., \& Clifton, C., Jr. (1999). Another word on parsing relative clauses: Eyetracking evidence from Spanish and English. Memory \& Cognition, 27, 826-833.

Clahsen, H., \& Felser, C. (2006a). Continuity and shallow structures in language processing. Applied Psycholinguistics, 27, 107-126.

Clahsen, H., \& Felser, C. (2006b). Grammatical processing in language learners. Applied Psycholinguistics, 27, 3-42.

Clahsen, H., \& Felser, C. (2006c). How native-like is non-native language processing? Trends in Cognitive Sciences, 10, 564-570.

Cole, P., Hermon, G., \& Sung, L.-M. (1990). Principles and parameters of long-distance reflexives. Linguistic Inquiry, 21, 1-22.

Cole, P., \& Sung, L.-M. (1994). Head movement and long distance reflexives. Linguistic Inquiry, 25, 355-406.

Cook, V. (1997). The consequences of bilingualism for cognitive processing. In A. M. B. de Groot \& J. F. Kroll (Eds.), Tutorials in bilingualism (pp. 279-299). Mahwah, NJ: Erlbaum.

Cuetos, F., \& Mitchell, D. (1988). Cross-linguistic differences in parsing: Restrictions on the use of the Late Closure strategy in Spanish. Cognition, 30, 73-105.

Dussias, P. (2001). Sentence parsing in fluent Spanish-English bilinguals. In J. Nicol (Ed.), One mind, two languages: Bilingual language processing (pp. 159-176). Malden, MA: Blackwell.

Dussias, P. (2003). Syntactic ambiguity resolution in L2 learners. Studies in Second Language Acquisition, 25, 529-557.

Dussias, P. E., \& Cramer Scaltz, T. R. (2008). Spanish-English L2 speakers' use of subcategorization bias information in the resolution of temporary ambiguity during second language reading. Acta Psychologica, 128, 501-513.

Dussias, P. E., \& Sagarra, N. (2007). The effect of exposure on syntactic parsing in Spanish-English bilinguals. Bilingualism: Language and Cognition, 10, 101-116.

Felser, C., \& Roberts, L. (2007). Processing wh-dependencies in a second language: A cross-modal priming study. Second Language Research, 23, 9-36.

Felser, C., Roberts, L., Marinis, T., \& Gross, R. (2003). The processing of ambiguous sentences by first and second language learners of English. Applied Psycholinguistics, 24, 453-489.

Fernández, E. (2003). Bilingual sentence processing. Amsterdam: John Benjamins. Ferreira, F. (2003). The misinterpretation of noncanonical sentences. Cognitive Psychology, 47, 164203.

Fernández, E. M. (2002). Relative clause attachment in bilinguals and monolinguals. In R. R. Heredia \& J. Altarriba (Eds.), Bilingual sentence processing (pp. 187-215). Amsterdam: Elsevier.

Ferreira, F., \& Patson, N. (2007). The good enough approach to language comprehension. Language and Linguistics Compass, 1, 71-83.

Fodor, J. D. (1998). Learning to parse. Journal of Psycholinguistic Research, 27, 285-319.

Fodor, J. D. (2002). Prosodic disambiguation in silent reading. In M. Hirotani (Ed.), NELS (Vol. 32, pp. 113-132). Amherst, MA: GLSA Publications.

Frazier, L. (1979). On comprehending sentences: Syntactic parsing strategies. Unpublished doctoral dissertation, University of Connecticut.

Frazier, L. (1987a). Sentence processing: A tutorial review. In M. Coltheart (Ed.), Attention and performance XII: The psychology of reading (pp. 601-681). Hove: Erlbaum. 
Witzel et al.: Deeper than shallow

Frazier, L. (1987b). Syntactic processing: Evidence from Dutch. Natural Language and Linguistic Theory, 5, 519-559.

Frazier, L., \& Clifton, C., Jr. (1996). Construal. Cambridge, MA: MIT Press.

Frazier, L., \& Clifton, C., Jr. (1997). Construal: Overview, motivation, and some new evidence. Journal of Psycholinguistic Research, 26, 277-295.

Frazier, L., \& Fodor, J. D. (1978). The sausage machine: A new two-stage parsing model. Cognition, $6,291-325$.

Frazier, L., \& Rayner, K. (1982). Making and correcting errors during sentence comprehension: Eye movements in the analysis of structurally ambiguous sentences. Cognitive Psychology, 14, $178-210$.

Frenck-Mestre, C. (1999). Examining second language reading: An on-line look. In A. Sorace, C. Heycock, \& R. Shillcock (Eds.), Language acquisition: Knowledge representation and processing (pp. 474-478). Amsterdam: North-Holland.

Frenck-Mestre, C. (2002). An on-line look at sentence processing in the second language. In R. R. Heredia \& J. Altarriba (Eds.), Bilingual sentence processing (pp. 217-236). Amsterdam: Elsevier.

Frenck-Mestre, C., \& Pynte, J. (1997). Syntactic ambiguity resolution while reading in a second and native language. Quarterly Journal of Experimental Psychology, 50A, 119-148.

Frenck-Mestre, C., \& Pynte, J. (2000). Resolving syntactic ambiguities: Cross-linguistic differences? In M. de Vincenzi \& V. Lombardo (Eds.), Cross-linguistic perspectives on language processing (pp. 119-148). Dordrecht: Kluwer.

Gibson, E., \& Pearlmutter, N. (1998). Constraints on sentence comprehension. Trends in Cognitive Sciences, 2, 262-268.

Gibson, E., Pearlmutter, N., Canseco-Gonzalez, E., \& Hickok, G. (1996). Recency preference in the human sentence processing mechanism: Evidence from English and Spanish. Cognition, 59, 23-59.

Gilboy, E., Sopena, J., Clifton, C., \& Frazier, L. (1995). Argument structure and association preferences in Spanish and English compound NPs. Cognition, 54, 131-167.

Grice, H. P. (1975). Logic and conversation. In P. Cole \& G. Morgan (Eds.), Syntax and semantics 3. New York: Academic Press.

Guillelmon, D., \& Grosjean, F. (2001). The gender marking effect in spoken word recognition: The case of bilinguals. Memory \& Cognition, 29, 503-511.

Hahne, A., \& Friederici, A. D. (2001). Processing a second language: Later learners' comprehension mechanisms as revealed by event-related brain potentials. Bilingualism: Language and Cognition, 4, 123-141.

Hemforth, B., Konieczny, L., \& Scheepers, C. (2000). Syntactic attachment and anaphor resolution: Two sides of relative clause attachment. In M. Crocker, M. Pickering, \& C. Clifton (Eds.), Architectures and mechanisms for language processing (pp. 259-282). Cambridge: Cambridge University Press.

Hill, R. L., \& Murray, W. S. (2000). Commas and spaces: Effects of punctuation on eye movements and sentence parsing. In A. Kennedy, R. Radach, D. Heller, \& J. Pynte (Eds.), Reading as a perceptual process (pp. 565-589). Oxford: Elsevier.

Hoeks, J. C. J., Hendriks, P., Vonk, W., Brown, C. M., \& Hagoort, P. (2006). Processing the noun phrase versus sentence coordination ambiguity: Thematic information does not completely eliminate processing difficulty. Quarterly Journal of Experimental Psychology, 59, 1581-1599.

Inoue, A., \& Fodor, J. D. (1995). Information-paced parsing in Japanese. In R. Mazuka \& N. Nagai (Eds.), Japanese sentence processing (pp. 9-63). Hillsdale, NJ: Erlbaum.

Jiang, N. (2004). Morphological insensitivity in second language processing. Applied Psycholinguistics, 25, 603-634.

Jiang, N. (2007). Selective integration of linguistic knowledge in adult second language learning. Language Learning, 57, 1-33.

Juffs, A. (1998a). Main verb vs. reduced relative clause ambiguity resolution in second language sentence processing. Language Learning, 48, 107-147.

Juffs, A. (1998b). Some effects of first language argument structure and syntax on second language processing. Second Language Research, 14, 406-424.

Juffs, A. (2004). Representation, processing, and working memory in a second language. Transactions of the Philological Society, 102, 199-225. 
Juffs, A., \& Harrington, M. (1996). Garden path sentences and error data in second language processing research. Language Learning, 46, 286-324.

Kamide, Y. (2006). Incrementality in Japanese sentence processing. In M. Nakayama, R. Mazuka, \& Y. Shirai (Eds.), The handbook of East Asian psycholinguistics: Japanese (pp. 249-256). Cambridge: Cambridge University Press.

Kennedy, A., Murray, W., \& Boissiere, C. (2004). Parafoveal pragmatics revisited. European Journal of Cognitive Psychology, 16, 128-153.

Kilborn, K. (1989). Sentence processing in a second language: The timing of transfer. Language and Speech, 32, 1-23.

Kilborn, K. (1992). On-line integration of grammatical information in a second language. In R. J. Harris (Ed.), Cognitive processing in bilinguals (pp. 337-368). Amsterdam: Elsevier.

Kimball, J. (1973). Seven principles of surface structure parsing in natural language. Cognition, 2, $15-47$.

Liu, R., \& Nicol, J. (2010). Online processing of anaphora by advanced English learners. In M. T. Prior, Y. Watanabe, \& S.-K. Lee (Eds.), Selected proceedings of the 2008 Second Language Research Forum (pp. 150-165). Somerville, MA: Cascadilla Proceedings Project.

MacDonald, M. C., Pearlmutter, N. J., \& Seidenberg, M. S. (1994). Syntactic ambiguity resolution as lexical ambiguity resolution. In C. Clifton, L. Frazier, \& K. Rayner (Eds.), Perspectives on sentence processing (pp. 123-153). Hillsdale, NJ: Erlbaum.

MacDonald, M. C., Pearlmutter, N. J., \& Seidenberg, M. S. (1995). The lexical nature of syntactic ambiguity resolution. Psychological Review, 101, 676-703.

MacWhinney, B. (1987). The competition model. In B. MacWhinney (Ed.), Mechanisms of language acquisition (pp. 249-308). Hillsdale, NJ: Erlbaum.

MacWhinney, B. (2002). Extending the competition model. In R. R. Heredia \& J. Altarriba (Eds.), Bilingual sentence processing (pp. 31-57). Amsterdam: Elsevier.

Marinis, T., Roberts, L., Felser, C., \& Clahsen, H. (2005). Gaps in second language sentence processing. Studies in Second Language Acquisition, 27, 53-78.

McConkie, G. W., \& Rayner, K. (1975). The span of the effective stimulus during a fixation in reading. Perception \& Psychophysics, 17, 578-586.

Mitchell, D. C., \& Cuetos, F. (1991). The origins of parsing strategies. In C. Smith (Ed.), Current issues in natural language processing (pp. 1-12). Austin, TX: University of Texas, Center for Cognitive Science.

Mitchell, D. C., Cuetos, F., Corley, M. M. B., \& Brysbaert, M. (1995). Exposure-based models of human parsing: Evidence for the use of coarse-grained (nonlexical) statistical records. Journal of Psycholinguistic Research, 24, 469-488.

Miyamoto, E. T. (2002). Case markers as clause boundary inducers in Japanese. Journal of Psycholinguistic Research, 31, 307-347.

Papadopoulou, D., \& Clahsen, H. (2003). Parsing strategies in L1 and L2 sentence processing. Studies in Second Language Acquisition, 25, 501-528.

Pritchett, B. L. (1991). Head position and parsing ambiguity. Journal of Psycholinguistic Research, 20, 251-270.

Rayner, K. (1998). Eye movements in reading and information processing: 20 years of research. Psychological Bulletin, 124, 372-422.

Rayner, K., \& Pollatsek, A. (1989). The psychology of reading. Hillsdale, NJ: Erlbaum.

Rayner, K., \& Sereno, S. C. (1994). Regressive eye movements and sentence parsing: On the use of regression contingent analyses. Memory \& Cognition, 22, 281-285.

Rayner, K., Well, A. D., Pollatsek, A., Bertera, J. H. (1982).The availability of useful information to the right of fixation in reading. Perception \& Psychophysics, 31, 537-550.

Schafer, A., Carter, J., Clifton, C., \& Frazier, L. (1996). Focus in relative clause construal. Language and Cognitive Processes, 11, 135-163.

Segalowitz, N. (2003). Automaticity and second languages. In C. Doughty \& M. Long (Eds.), The handbook of second language acquisition (pp. 382-388). Oxford: Blackwell.

Shen, X. (2006). Late assignment of syntax theory: Evidence from Chinese and English. Unpublished doctoral dissertation, University of Exeter.

Soh, H. L. (1998). Object scrambling in Chinese. Unpublished doctoral dissertation, Massachusetts Institute of Technology. 
Witzel et al.: Deeper than shallow

Staub, A. (2010). Eye movements and processing difficulty in object relative clauses. Cognition, 116, 71-86.

Townsend, D. J., \& Bever, T. G. (2001). Sentence comprehension: The integration of habits and rules. Cambridge, MA: MIT Press.

Traxler, M. J., Pickering, M. J., \& Clifton, C., Jr. (1998). Adjunct attachment is not a form of lexical ambiguity resolution. Journal of Memory and Language, 39, 558-592.

Trueswell, J., \& Tanenhaus, M. (1994). Toward a lexicalist framework for constraint-based syntactic ambiguity resolution. In C. Clifton, L. Frazier, \& K. Rayner (Eds.), Perspectives on sentence processing (pp. 155-179). Hillsdale, NJ: Erlbaum.

Warren, T., White, S. J., \& Reichle, E. D. (2009). Investigating the causes of wrap-up effects: Evidence from eye movements and E-Z Reader. Cognition, 111, 132-137.

Witzel, J. D., \& Witzel, N. O. (2011). The processing of Japanese control sentences. In H. Yamshita, J. Packard, \& Y. Hirose (Eds.), Processing and producing head-final structures (pp. 23-47). London: Springer.

Witzel, N., Witzel, J., \& Forster, K. (in press). Comparisons of online reading paradigms: Eye tracking, moving window, and maze. Journal of Psycholinguistic Research.

Yuan, B. (1998). Interpretation of binding and orientation of the Chinese reflexive ziji by English and Japanese speakers. Second Language Research, 14, 324-340.

Zagar, D., Pynte, J., \& Rativeau, S. (1997). Evidence for early closure attachment on first-pass reading times in French. Quarterly Journal of Experimental Psychology, 50A, 421-438. 